\title{
Development and operating experience of a 1.2-m long helical superconducting undulator at the Argonne Advanced Photon Source
}

\author{
M. Kasa $\odot$, M. Borland, L. Emery, J. Fuerst, K. C. Harkay, Q. Hasse, Y. Ivanyushenkov, \\ W. Jansma๑, I. Kesgin, V. Sajaev, Y. Shiroyanagi॰, Y. P. Sun, and E. Gluskin \\ Advanced Photon Source, Argonne National Laboratory, \\ 9700 South Cass Avenue, Lemont, Illinois 60439, USA
}

(Received 21 October 2019; accepted 6 May 2020; published 18 May 2020)

\begin{abstract}
Development of superconducting undulators (SCUs) continues at the Advanced Photon Source (APS). Several planar SCUs were designed and built, and two of them are currently in operation at the APS. In January 2018 a new helical SCU (HSCU) was installed on the storage ring at the APS. It has a $1.2 \mathrm{~m}-\mathrm{long}$ magnet with bifilar winding that generates on its axis a single harmonic of about $6 \mathrm{keV}$ x-rays. The magnet is housed in the newly designed compact cryostat equipped with four cryocoolers. The HSCU was extensively tested prior to its installation on the APS storage ring, and it demonstrated cryogenic and magnetic performance in accordance with the design specifications. The HSCU was rapidly and successfully commissioned, and in February 2018 it was transferred to user operations. Its performance as an X-ray radiation source has been studied and spectral characteristics confirmed. The HSCU is currently used to support unique scientific program at the APS.
\end{abstract}

DOI: 10.1103/PhysRevAccelBeams.23.050701

\section{INTRODUCTION}

The design and construction of a novel HSCU has been completed at the Advanced Photon Source (APS) at Argonne National Laboratory (ANL). This undulator was successfully tested in a newly designed cryostat, and finally went through rigorous magnetic characterization prior to its installation on the APS storage ring. In January 2018, the HSCU was installed and became the first such device on a 3rd-generation storage ring. Following installation, the HSCU was rapidly and successfully commissioned and in February it became available for user operations.

Alferov, et al. first analyzed the generation of circularly polarized radiation and proposed a source using a bifilar helical coil arrangement with one helix offset from the other by one half of an undulator period [1]. During the 1970s, an HSCU was developed for FEL experiments at Stanford [2]. In 1984, an HSCU was installed in a straight section of the VEPP-2M storage ring in Novosibirsk to measure the polarization of the electron-positron colliding beams [3]. And in the early 2000s, several HSCU prototypes for the International Linear Collider were fabricated and measured in a liquid helium bath cryostat [4]. The effects of the magnetic fields on an electron beam at the

Published by the American Physical Society under the terms of the Creative Commons Attribution 4.0 International license. Further distribution of this work must maintain attribution to the author(s) and the published article's title, journal citation, and DOI. entrance and exit of a helical undulator have been analyzed and various geometries of a coil have been proposed $[5,6]$.

The motivation for development and construction of such a device is two-fold. First, a helical undulator provides the experimentalist with unique spectral properties of radiation. Specifically, on axis helical undulators emit a single first harmonic allowing for optics-monochromator free experimental setups. Second, use of a helical style undulator as a radiation amplifier would lead to the development of a future generation of record powerful FELs [7]. Utilization of classical (round aperture) helical undulators at synchrotron radiation facilities was restricted mostly by the beam injection requirements; but 4th-generation light sources with on-axis injection would eliminate such a restriction. An HSCU with an on-axis field higher than any other in that class of undulators would become an attractive choice for many experiments. Magnetic simulations suggest and recent experimental results clearly prove that superconducting technology can provide an on-axis undulator field higher than permanent magnet technology for both planar and helical undulators. It has also been demonstrated at the APS and ANKA [8] that planar SCUs could be built and operated under stringent requirements applied to 3rd-generation light sources and FELs. Therefore, the focus of this project was to develop and build a helical undulator that incorporates the benefits of superconducting technology and to demonstrate the ability of an HSCU to meet the operational requirements of the APS storage ring.

The first planar SCU to be incorporated into the APS storage ring, SCU0 [9], was $0.33 \mathrm{~m}$ long with a $16 \mathrm{~mm}$ 
period. SCU0 was in operation in sector 6 from January 2013 through September 2016. Operating in sector 1 of the APS since May 2015 is SCU18-1 which is a $1.1 \mathrm{~m}$-long planar SCU with an $18 \mathrm{~mm}$ period [10]. SCU18-2 has the same dimensions as SCU18-1, but incorporates additional features that reduce the phase errors of the device to less than $2^{\circ}$ rms over the entire operating range without magnetic tuning. SCU18-2 replaced SCU0 in sector 6 in September 2016.

The cryostat design for the planar SCUs is based on the cryostat for superconducting wigglers developed at the Budker Institute of Nuclear Physics (BINP) in Novosibirsk $[11,12]$. Referred to as the 1st-generation cryostat, it is a cryocooler-based system that provides three stages of cooling to intercept thermal radiation, beam chamber heating due to electron beam heat loads, and a magnet cooling circuit to maintain the superconducting magnets at liquid helium (LHe) temperatures. Included in the magnet cooling circuit is a LHe tank and sufficient cooling capacity is available at LHe temperatures to allow for zero LHe boil off operation of the cryogenic system. Part of this project included a redesign of the cryostat to reduce its fabrication cost, provide increased installation versatility, and simplify the assembly procedure. Several years of SCU operational experience guided the design of the 2nd-generation cryostat that has been used to house the HSCU $[13,14]$.

Since a helical undulator emits on axis a single 1st harmonic, the heat load within the axis vicinity is much smaller when compared with the heat load of a planar undulator with equal magnetic field and period. As a result,

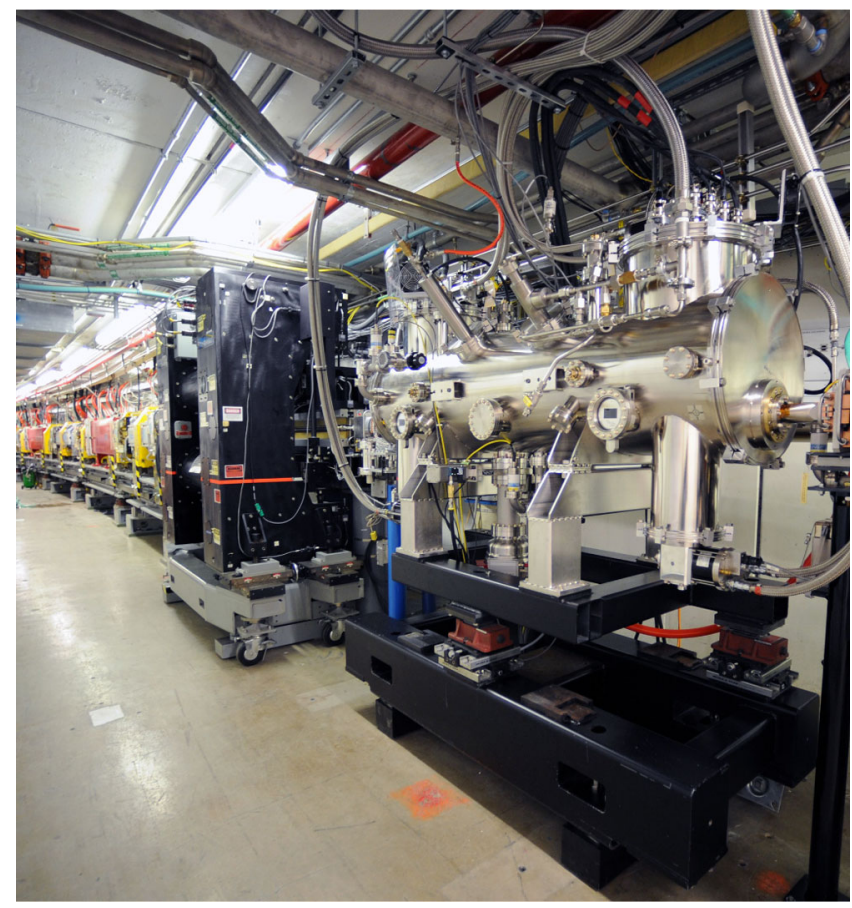

FIG. 1. Helical superconducting undulator installation on the APS storage ring. a beam line has the opportunity to greatly increase the central aperture flux by eliminating the need for optical components, including a monochromator. Another distinctive characteristic of helical undulators is that the emitted on-axis radiation is circularly polarized.

Installation of the HSCU in the storage ring tunnel, see Fig. 1, at this location was chosen due to a white-beam experimental station that will enable characterization of the HSCU and will also permit testing of new experimental setups for coherence-based x-ray scattering techniques. These techniques would see dramatic quantitative and qualitative enhancements with an X-ray source such as an HSCU.

In this paper we first give a concise description of the HSCU, with an emphasis on magnetic design and the development of a new cryostat. We then describe the results of a stand-alone cool down test, including magnetic measurements and cryogenic behavior of the HSCU. Finally, we present our experience operating the HSCU in the APS storage ring by describing the observed heat loads in the HSCU, the undulator performance, and its effect on the electron beam.

\section{DESIGN OF THE HSCU}

The x-ray energy range utilized for coherence-based $\mathrm{x}$-ray scattering experiments at the HSCU installation location is within $6.5 \mathrm{keV}$ to $10 \mathrm{keV}$. This range and allowable by APS storage ring operational requirements aperture of the vacuum chamber in the HSCU primarily affect the choice of undulator period. In addition, the energy bandwidth should be as low as possible in order to use x-rays without a monochromator. The selection of undulator period and peak magnetic field for fixed x-ray energy was conducted by using a Pareto-optimal approach, similar to that described in [15]. The quantities of interest include maximizing the flux for $6.5 \mathrm{keV}$ and $10 \mathrm{keV}$, minimizing the fractional energy half-width of the pinhole flux vs energy, maximizing the required beta function at the device, and maximizing the horizontal physical aperture. A model was created giving the maximum field - and thus the maximum $\mathrm{K}$ value - as a function of the winding radius and period. The winding radius directly determines the physical aperture. The set of data for evaluation was generated by computing the maximum field over a grid with periods ranging from $25 \mathrm{~mm}$ to $40 \mathrm{~mm}$ in $0.25 \mathrm{~mm}$ steps and winding radii ranging from $5 \mathrm{~mm}$ to $21 \mathrm{~mm}$ in $0.125 \mathrm{~mm}$ steps. The set consisted of 7,869 cases and the selection process started by confining to cases where the corresponding maximum $\mathrm{K}$ value is large enough to allow reaching a first harmonic energy of $6.5 \mathrm{keV}$. The remaining 2502 cases were studied to determine the pinhole flux at $6.5 \mathrm{keV}$ and the flux spectrum, which was facilitated by the commandline interfaces to the programs sddsfluxcurve [16] and SPECTRA [17]. Using nondominated sorting [18], 57 cases were found to be Pareto-optimal, which was reduced to 30 by requiring a beta function of $10 \mathrm{~m}$ or more. 
TABLE I. Design parameters of the HSCU.

\begin{tabular}{lc}
\hline \hline Parameter & Value \\
\hline Electron beam energy $(\mathrm{GeV})$ & 7 \\
Photon energy at the fundamental $(\mathrm{keV})$ & $6-12$ \\
Period length (mm) & 31.5 \\
Number of periods & 38.5 \\
Electron beam aperture $(\mathrm{mm})$ & $26 \mathrm{~h} \times 8 \mathrm{v}$ \\
Magnetic diameter $(\mathrm{mm})$ & 29 \\
Coil pack inner diameter $(\mathrm{mm})$ & 31 \\
Coil pack dimensions $(\mathrm{mm})$ & $9.21 \mathrm{~h} \times 8.09 \mathrm{v}$ \\
Conductors per helix & 138 \\
Bare conductor diameter $(\mathrm{mm})$ & 0.7 \\
On-axis magnetic field $(\mathrm{T})$ & $0.41\left(B_{x}=B_{y}\right)$ \\
Undulator parameter K & $1.2\left(K_{x}=K_{y}\right)$ \\
\hline \hline
\end{tabular}

These cases revealed a near-linear relationship between the optimal beam aperture and period, with shorter apertures providing higher x-ray flux. As a result, a period of $31.5 \mathrm{~mm}$ and a physical aperture of $\pm 13 \mathrm{~mm}$ were chosen. The limiting factor was the desire to avoid beta functions smaller than $10 \mathrm{~m}$ at the device location-a somewhat arbitrary limitation that was imposed to minimize the required lattice function changes (the nominal horizontal beta function at the device location is $20 \mathrm{~m}$ ).

The results of the optimization provided guidance for the final undulator specifications. A magnetic model, using Radia [19], was created in order to determine the geometry of the coil pack and operating current sufficient to achieve the peak magnetic field at the given period. Also, the synchrotron radiation heating of the vacuum chamber was analyzed, and results of this analysis were taken into account while converging on the final HSCU parameters. Table I summarizes the design parameters of the HSCU and some of the parameters are illustrated in Fig. 2.

\section{A. Magnet design and fabrication}

Several factors were considered during the design of the magnetic structure to create the helical undulator field using a bifilar helical coil arrangement [1] with one helix offset
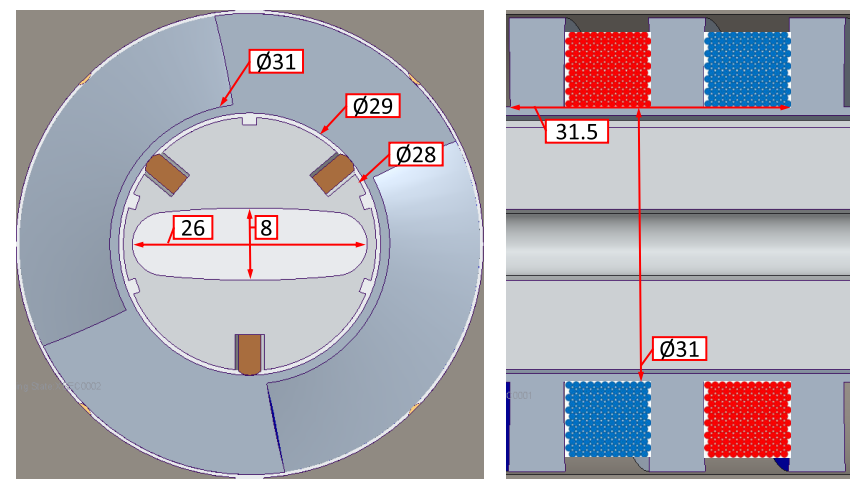

FIG. 2. Cross sections of the HSCU magnet and beam chamber, all dimensions in $\mathrm{mm}$. from the other by one half of an undulator period. The main questions that needed to be answered were the choice of conductor, coil pack dimensions, winding mandrel and impregnation mold material, how to support and cool the completed magnet inside the cryostat, and how to transition to the adjacent helix. Along with these factors it was desirable to achieve three goals. First, to wind the entire magnet continuously; second, to gradually reduce the end field of the undulator to control the effects on an electron beam at the entrance and exit as previously analyzed for various geometries [5,6]; and third, to simplify the geometry and machining of the mold/strongback used for epoxy impregnation and housing of the magnet inside the cryostat. Several short prototypes of the HSCU with a period of $20 \mathrm{~mm}$ and bore diameter of $15 \mathrm{~mm}$ were manufactured to test different winding schemes followed by a $0.3 \mathrm{~m}$-long prototype of the final design.

\section{Winding concept}

Conceptually, a helix is a line with a slope that is wrapped around a cylinder. A bifilar helix consists of two sloped lines, separated by a distance, wrapped around a cylinder. The slope of the line determines the lead, or period, of the helix, as shown in Fig. 3.

A winding concept was developed that allowed the undulator to be wound with a single conductor without any resistive or mechanical junctions. A second feature of the concept is that pins used to transition the conductor between adjacent helical grooves do not extend beyond the diameter of the winding mandrel. This approach differs from previous winding techniques that used ribbon cable, like in [4], which required mechanical junctions and transition pins located on a flange that extended beyond the diameter of the undulator winding groove.

Transitioning from one helix to the other at the ends of the device by completing a $180^{\circ}$ turn around a pin extending radially from the cylinder. The number of pins and the diameter of each pin depends on the number of conductors in a full layer and the pins were distributed around the last two periods at each end of the device. It is

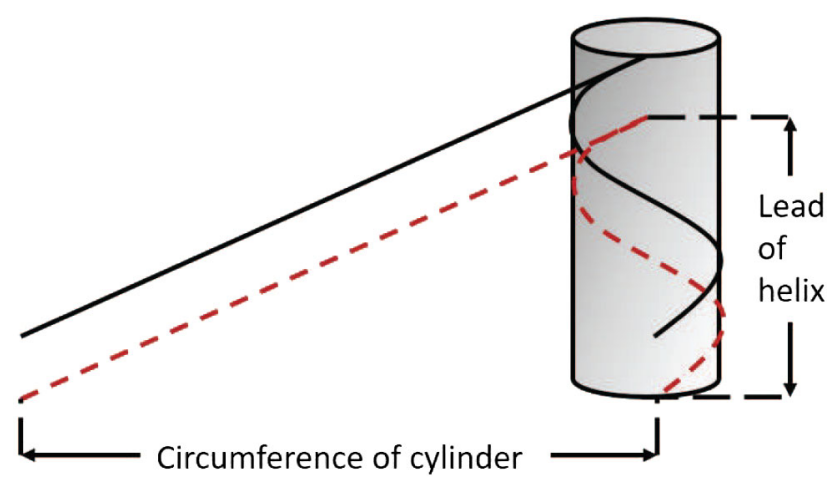

FIG. 3. Helix being formed by rotating a line with a slope around a cylinder. 


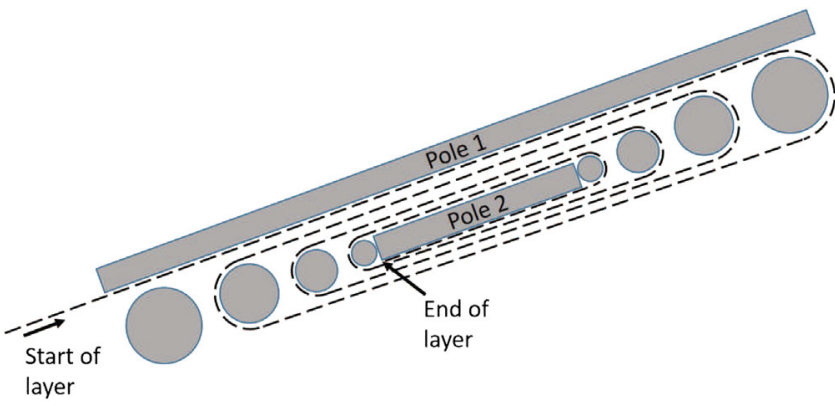

FIG. 4. Path of the conductor in an unwound bifilar helical structure.

easiest to imagine the path of the conductor if the bifilar helix structure is unwound, as in Fig. 4.

In the figure a simplified structure is shown as an example of winding a bifilar helical structure with four conductors in a full layer. The first layer starts at one end of the device, next to the largest turn-around pin, and is wound around the cylinder until the large turn-around pin at the other end is reached. After completing the turn-around, the conductor is wound in the adjacent helix back to the starting end of the cylinder, where it winds around the second-to-last turn-around pin. In effect, the conductor is spiraling in toward the smaller pins. This process continues until the end of the layer is reached at the smallest pin at the starting end. The next layer, which contains only three conductors in this example, is wound over the previous layer so that it spirals out toward the largest pin, and the smallest pins are not used. The process continues in this way until the desired number of layers is reached.

Winding with this concept addresses all three goals: continuous winding of the helical structure is achieved, the number of turns in the coil pack is gradually reduced as the end of the device is reached, and the height of the poles and the pins can be at the same height allowing the wound magnet to have a uniform outer diameter which greatly simplifies the machining of the mold structure. As was previously stated, the number of pins depends on the number of turns in a full layer and they can be evenly distributed over any number of periods. The width of the smallest pin is the same as the pole width and the diameter of the next size pin increases by twice the conductor width. Since the conductor stacks vertically around the pins, the height of the pin is equal to the product of the number of layers and the conductor diameter. This height is greater than the full coil pack with the layers wound such that the conductors stack in a nested configuration and the height is equal to $D\left[(N-1) \sin \left(\frac{\pi}{3}\right)+1\right]$, where $\mathrm{D}$ is the conductor diameter and $\mathrm{N}$ is the number of layers.

\section{Prototypes and final design}

The first prototypes manufactured to test the proposed winding concept were two $0.3 \mathrm{~m}$-long helical mandrels

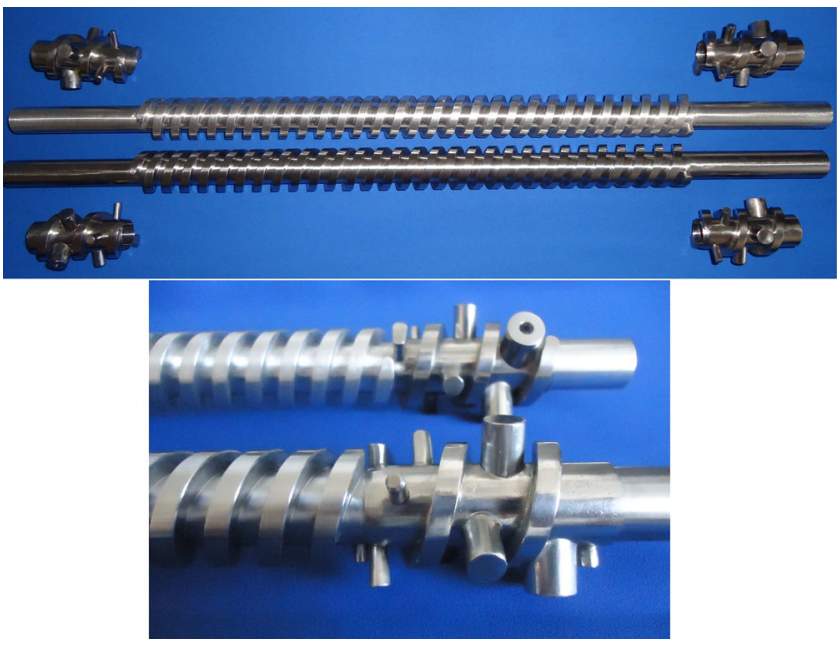

FIG. 5. Top: Al and 1020 steel, 20 mm-period prototype HSCU mandrels with the DMLS turn-around structures not installed. Bottom: One end of the prototypes with the turn-around structures installed.

with a $20 \mathrm{~mm}$ period and a winding bore of $15 \mathrm{~mm}$. One was made of aluminum (Al) and the other of 1020 steel. Structures to test the conductor turn-around concept were made using the direct metal laser sintered (DMLS) process in both stainless and 1020 steel, see Fig. 5.

Both prototype mandrels were continuously wound with type 56S53, $0.6 \mathrm{~mm}$-diameter, niobium titanium (NbTi) superconductor from Supercon, Inc. [20], as shown in Fig. 6.

The groove dimensions allowed 53 conductors to be precisely wound in each helix, but due to a combination of developing the winding procedure and the dimensions of the turn- around structure not being correct, the coil pack exceeded the height of the poles. Nonetheless, the turnaround concept proved to be viable, and its development proceeded. Both prototype cores were epoxy impregnated

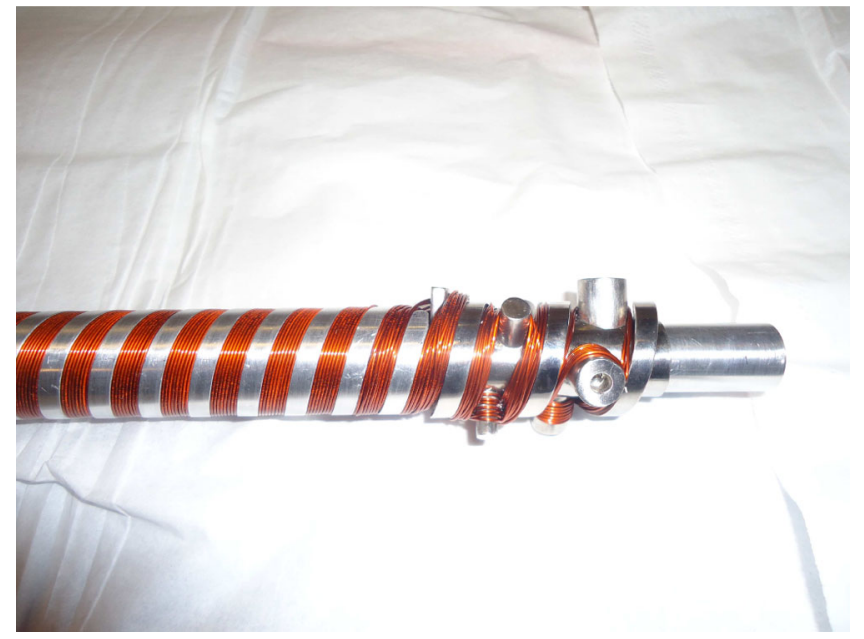

FIG. 6. The 20-mm-period, aluminum prototype magnet after winding. 
and measured magnetically in a LHe bath cryostat. Magnetic measurements confirmed the modeling results that the steel mandrel provided a field gain of $\sim 25 \%$ at currents above 300 A along with a field gain of almost $8 \%$ with a steel mold/strongback. There were also concerns of the steel mandrel short circuiting the field as the inner diameter of the mandrel was also steel. Magnetic modeling and measurement data concluded this was not an issue and the short circuiting effect is negated due to the fact that the pole is also extended, thereby reducing the magnetic diameter of the magnet. The measurement results are described in detail in Sec. III B.

Improvements to the turn-around structure were made based on lessons learned from the first prototypes and the final design proceeded with the magnet parameters specified in Table I. Rather than manufacture a turn-around structure using the DMLS process, it was decided to integrate the pins directly into the mandrel. Pilot pins were machined into the mandrel, and sleeves of various diameters were manufactured to slide over the pilot pins. Extensions to the pins were made to facilitate the turnaround process during winding. The extensions were designed to be removed after winding, leaving the pins and the helical poles at the same height. Figure 7 shows the model of the integrated turn-around concept that was developed.

A $0.3 \mathrm{~m}$-long prototype mandrel with a $31.5 \mathrm{~mm}$ period was machined to test the integrated design and machining techniques. Based on the results of the first prototypes, the mandrel and mold/strongback were fabricated from steel and wound using type 56S53, $0.7 \mathrm{~mm}$-diameter, NbTi superconductor from Supercon, Inc. Due to chamfers at the base of the groove and the specified pole height being less than needed, the number of conductors per helix on the short prototype was 115 instead of the intended 138. Figure 8 shows the last couple of periods and the turnaround section of the wound prototype core. The pin extensions have been removed, leaving a uniform outside diameter of the structure to be placed in the mold for epoxy impregnation.

Following the successful conclusion of the prototype program, the $1.2 \mathrm{~m}$ full-length HSCU mandrel was machined from steel. Figure 9 shows the $1.2 \mathrm{~m}$-long mandrel being machined on the lathe along with three

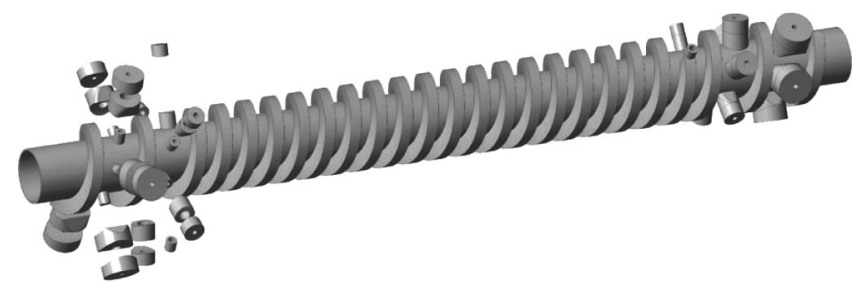

FIG. 7. Computer model of the integrated turn around concept with the turn-around sleeves and extensions in an exploded view on the left side and installed for winding on the right side.

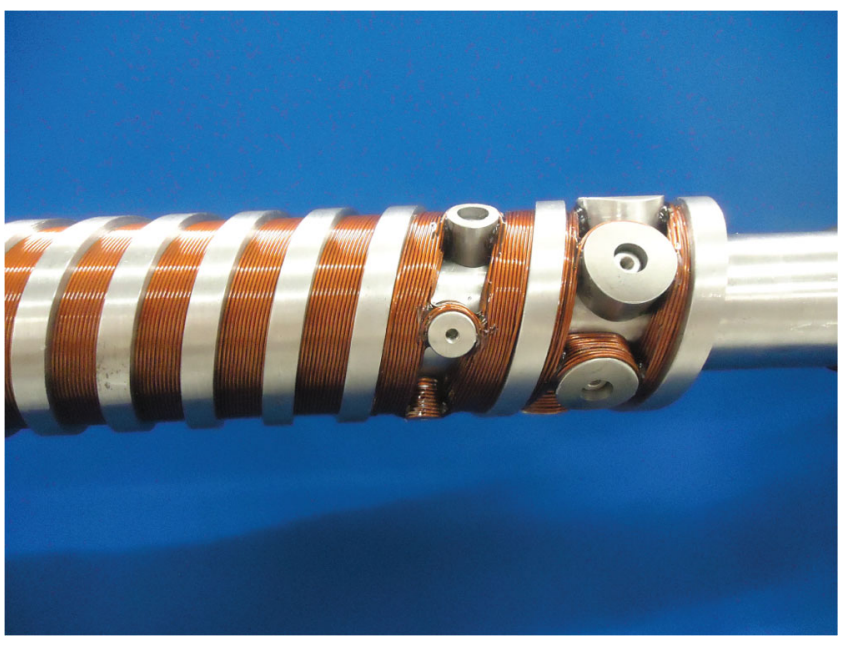

FIG. 8. The $0.3 \mathrm{~m}$-long, $31.5 \mathrm{~mm}$ period prototype HSCU after winding. The turn-around extensions have been removed.

support fixtures that were in place during the process. These support fixtures were in place during machining to aid in achieving the tolerances of the diameter of the winding groove which was specified to be $31 \pm 0.02 \mathrm{~mm}$. The tooling and supports were developed during the fabrication of the prototype cores.

The full-length machined mandrels were wound with type 56S53, $0.7 \mathrm{~mm}$-diameter, $\mathrm{NbTi}$ superconductor from Supercon, Inc. With the correct dimensions and refinement of the machining process, these mandrels were continuously wound with 138 conductors in each helix with a single conductor, as shown in Fig. 10. Ready for epoxy impregnation, the mandrel was placed in the steel mold, see Fig. 11.

After impregnation the magnet remains in the mold, which serves as a strongback for support and a means for cooling the magnet during operation in the cryostat. Due to

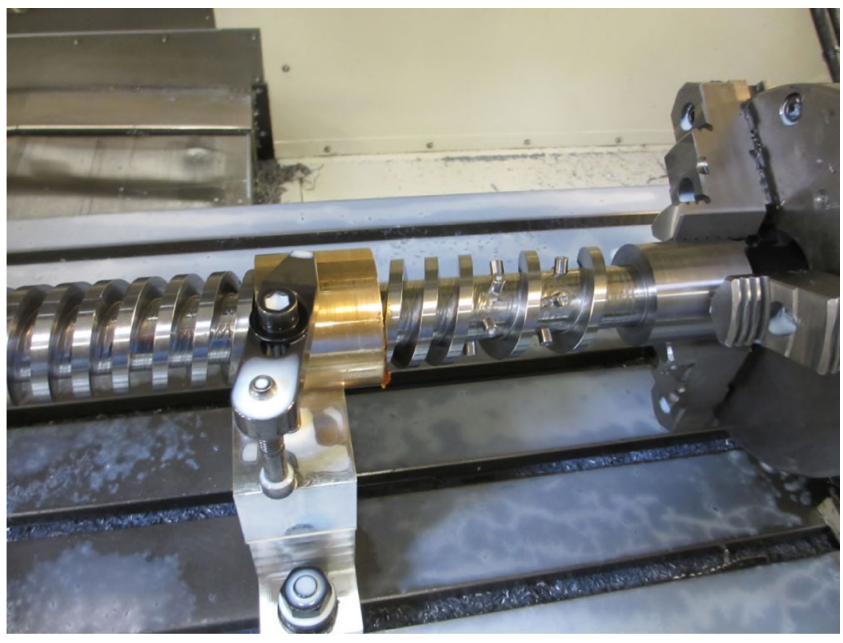

FIG. 9. The $1.2 \mathrm{~m}$ long HSCU mandrel during the machining process showing one of three support fixtures. 


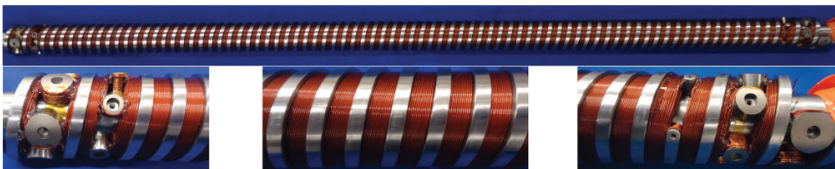

FIG. 10. HSCU magnet after winding. The pin extensions have been removed in preparation for epoxy impregnation.

the mechanical structure of the HSCU assembly, the magnet cannot be cooled via LHe through a channel in the mandrel like the planar SCUs developed at the APS [1,2]; therefore, we decided to place the LHe channels in the mold. The completed magnet and mold assembly was tested in the vertical LHe bath cryostat and, after the final assembly, in the horizontal cryostat.

\section{Corrector magnets}

Corrector magnets were also designed and manufactured to provide field integral correction. The need for the corrector magnets was recognized when evaluating the results of the magnetic model and the prototype measurements. Vertical and horizontal superconducting dipole corrector magnets constructed from 1018 steel were designed to be mounted at each end of the magnet mold (see Fig. 12) with copper supports to provide cooling.

The purpose of the corrector magnets was to correct for a nonzero first field integral at each end of the magnet. Since there was no evidence of a distributed dipole field along the length of the magnet, the required values of correction did not scale with length from the short prototypes to the full length magnet. Therefore the upstream corrector serves as a 2nd field integral corrector and the downstream magnet corrects the 1st field integral. The anticipated maximum value of correction was $3000 \mu \mathrm{T}-\mathrm{m}$ and the magnetic design was completed in Comsol. The design current of the correctors was $46 \mathrm{~A}$ and the magnets were fabricated and wound with 58 turns of $0.4 \mathrm{~mm} \mathrm{NbTi}$ superconductor from Supercon, Inc.

\section{Magnetic model}

A model of the HSCU was developed using the Radia software package and Mathematica. Characteristics such as winding diameter, coil dimensions, period, current, and number of periods were parametrized in the model. The coil

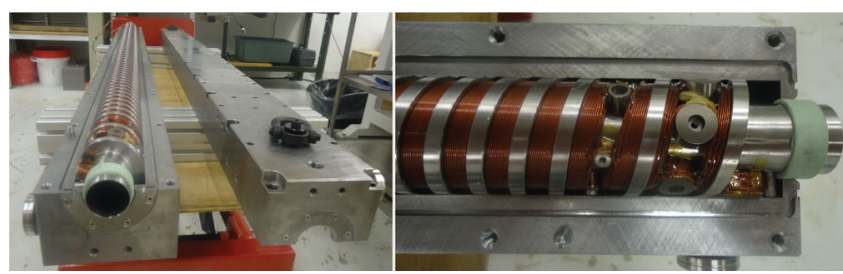

FIG. 11. HSCU magnet test fit into the mold before epoxy impregnation.

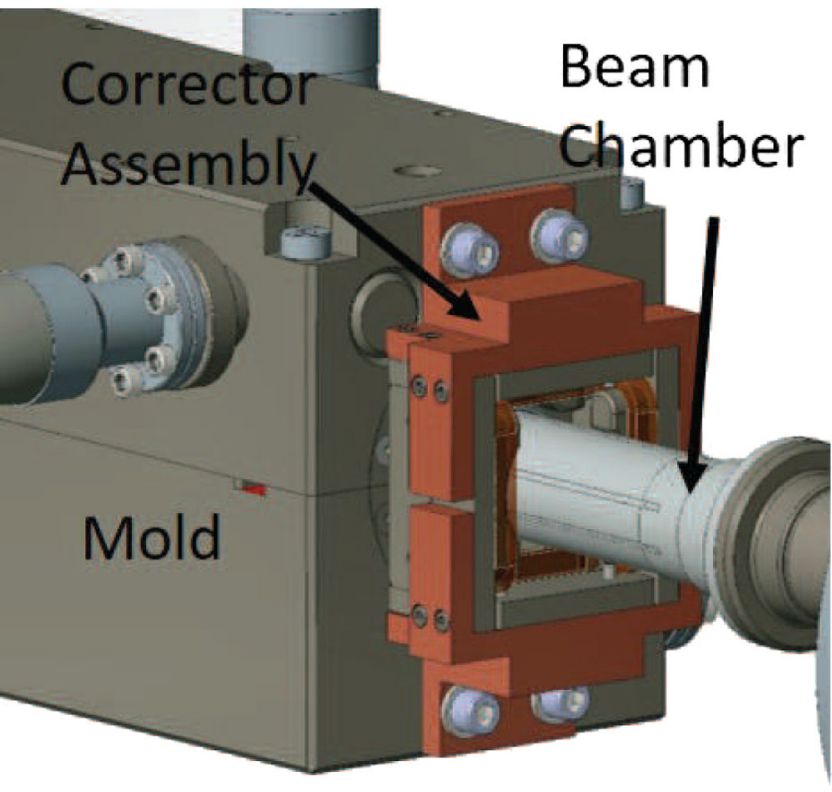

FIG. 12. Rendering of the HSCU assembly showing the corrector magnets mounted to the end of the mold as well as the beam chamber extending outside of the assembly.

pack is modeled as a bulk conductor and is not comprised of individual conductors. By varying the parameters in the model we were able to determine the coil pack geometry and the optimal number of turns needed to reach the required peak field value to provide photons in the energy range desired by the beamline. An approximation to the end turn-around design as well as the steel mold were incorporated into the model. A graphic of a 13.5-period model with a $31.5 \mathrm{~mm}$ period is shown in Fig. 13; the steel mold is not shown.

As a result of the simulations and choosing a reasonable number of conductors in the helical coil pack, the geometry of the helical core and coil pack shown in Table I was reached. Along with the temperature, the magnetic field applied to the conductor determines the critical current of the superconductor. As can be seen in Fig. 14, the geometry of the HSCU results in a critical current of approximately $660 \mathrm{~A}$ at a field inside the coil pack of $4.5 \mathrm{~T}$ and a temperature of $4.2 \mathrm{~K}$. Conventionally, superconducting magnets are limited during operation at $80 \%$ of the critical current to provide stability. At this operating point the onaxis field of the HSCU is $0.44 \mathrm{~T}$, which is greater than the beamline required field of $0.41 \mathrm{~T}$ to reach a photon energy of $6 \mathrm{keV}$. Figure 14 shows the required field is attained at an

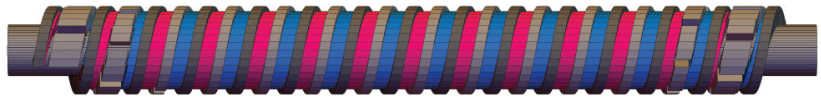

FIG. 13. A model of the HSCU with 13.5 periods and a period length of $31.5 \mathrm{~mm}$. The end turn-around structure is approximated and the steel mold is not shown, although the mold is included in the model and results. 


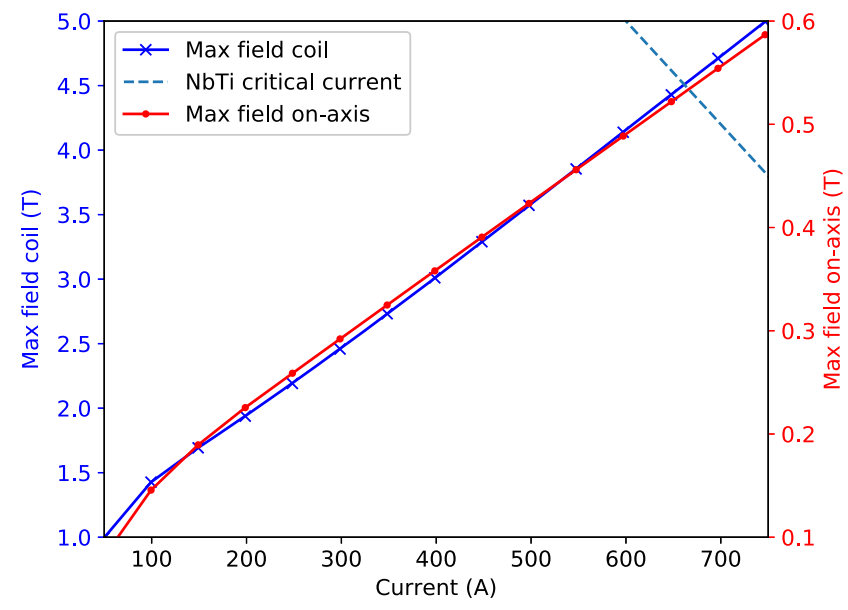

FIG. 14. Maximum field inside the NbTi coils and on-axis of the HSCU magnetic design. The dashed line represents the critical curve of the $0.7 \mathrm{~mm} \mathrm{NbTi}$ from Supercon at $4.2 \mathrm{~K}$. The expected operating point from the model is $475 \mathrm{~A}$.

approximate current of 475 A which is $72 \%$ of the critical current, providing additional operational stability. With a nominal operation temperature of $4.2 \mathrm{~K}$ the temperature margin is expected to be $\sim 1 \mathrm{~K}$.

The model also indicated the need for field integral correctors upstream and downstream of the HSCU. Due to the reduction of the coil pack over the last two periods of the device, the field gradually decays. However, due to the steel poles and mold, the first field integral is nonzero at the ends of the HSCU. Simulation results at 450 A of the horizontal and vertical fields along with the field integrals are shown in Fig. 15.

Although the longitudinal field is canceled in the center of the helical undulator, the model revealed a strong longitudinal field at the ends with a peak value over $0.6 \mathrm{~T}$, see Fig. 16. The presence of this field raised a concern regarding a coupling perturbation of the stored
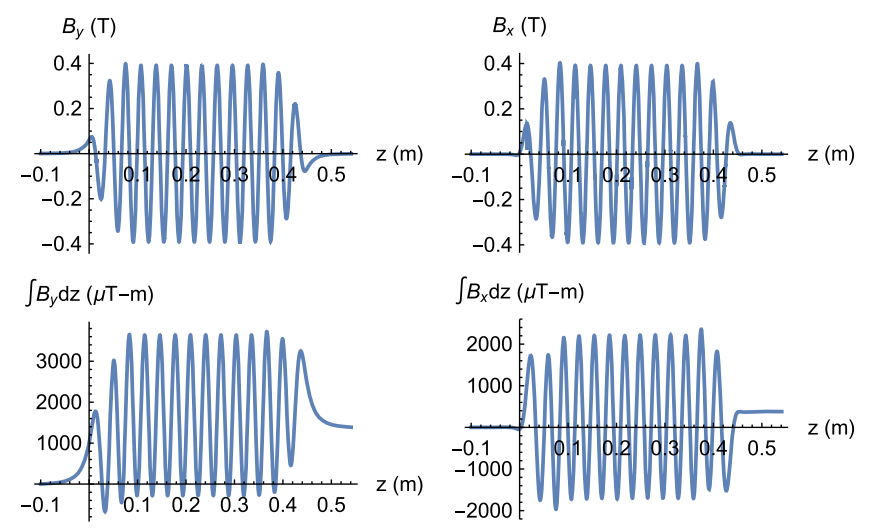

FIG. 15. Results of the Radia model simulation of the HSCU 13.5 period model. Top left: Vertical field. Top right: Horizontal field. Bottom left: Vertical first field integral. Bottom right Horizontal first field integral.

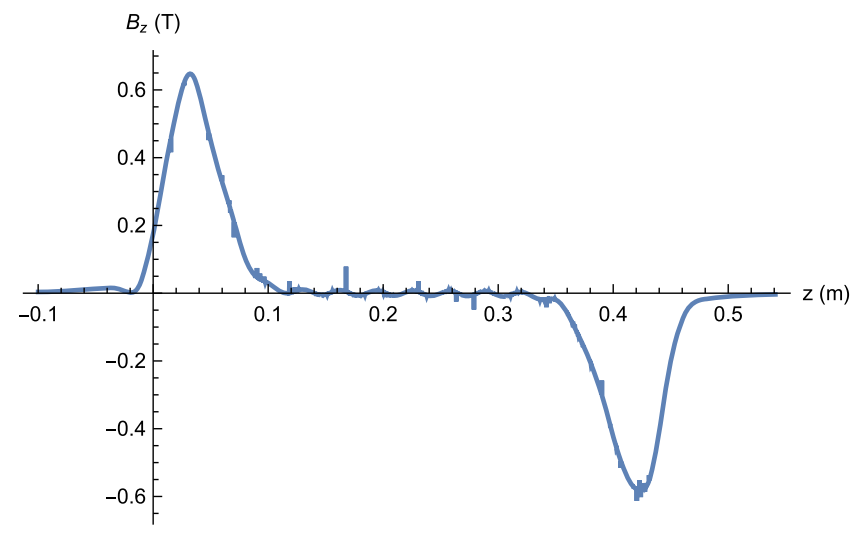

FIG. 16. On-axis longitudinal field from the Radia model simulation.

electron beam during operation in the APS storage ring. This prompted a detailed beam dynamics simulation, which confirmed that the presence of such a field would not affect APS storage ring operations [21].

\section{B. Beam vacuum chamber}

The bore diameter of the HSCU magnet core is $29 \mathrm{~mm}$. It accommodates an $\mathrm{Al}$ vacuum chamber with outer diameter of $28 \mathrm{~mm}$ and an elliptically shaped opening $(26 \mathrm{~mm}$ horizontal by $8 \mathrm{~mm}$ vertical) for the electron beam. Pictures of the vacuum chamber extrusions before machining to the final dimensions and one after welding to the room temperature transition flange are shown in Fig. 17.

The vacuum chamber must be thermally isolated from the HSCU core as much as possible to prevent beam induced heating from reaching the magnet cooling circuit. Due to the closed geometry of the undulator core the beam chamber is required to be supported by the internal bore of the magnet and the thermal links to the vacuum chamber can only be placed at its ends. This limitation requires that the vacuum chamber have a thermal conductivity as large as possible to conduct the heat from the center of the chamber to the thermal links at the ends. In order to increase the cross sectional area for thermal conduction, the beam aperture was chosen to be elliptical in shape, rather than circular. Torlon pins were used as low thermal heat leak

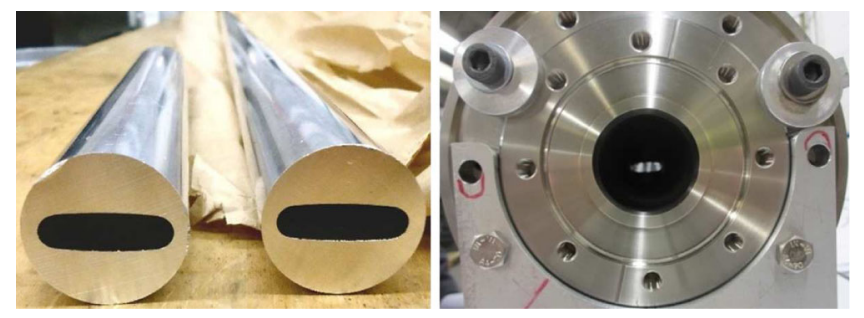

FIG. 17. HSCU vacuum chamber. Left: Al extrusions before machining; right: vacuum chamber is welded to the room temperature transition flange. 


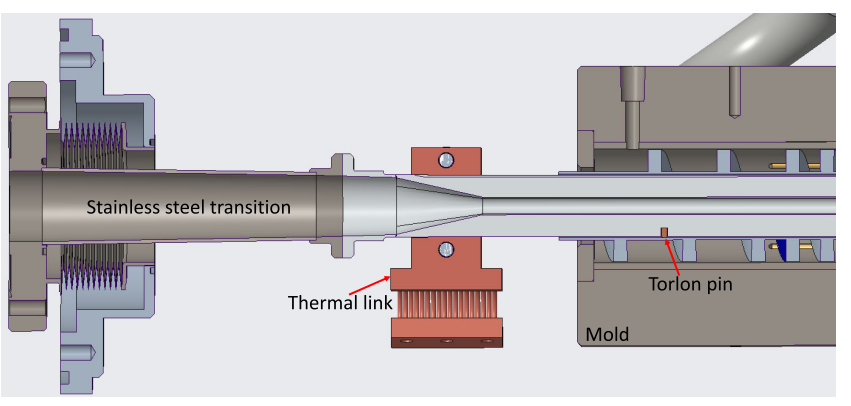

FIG. 18. Features of the HSCU beam chamber design showing the transition from room temperature, location of the thermal link outside of the magnet/mold structure, and the torlon pins used as a low heat leak support between the chamber and the magnet.

supports to center the beam chamber in the magnet bore. The heat leak from room temperature to the system through the beam chamber was limited through the use of stainless steel transitions. These features are displayed in Fig. 18 and Fig. 2.

\section{Cryostat}

Part of the HSCU project included a complete redesign of the cryostat that was previously used for the planar SCUs at the APS. Referred to as the 2nd-generation cryostat, the new design remains cryocooler based but utilizes many industry standard components to lower the production cost and the overall diameter from $0.95 \mathrm{~m}$ to $0.51 \mathrm{~m}$, and reduces the LHe tank capacity from $100 \mathrm{~L}$ to $30 \mathrm{~L}$. One major design difference is the 2nd-generation cryostat has two cooling circuits compared to three in the 1st-generation cryostat. A picture of both cryostats side by side is shown in Fig. 19.

In the 1st-generation cryostat the cold mass assembly was supported by Kevlar strings; the new design uses Invar rods to suspend the cold mass within the cryostat. Also incorporated into the design is the ability to monitor the

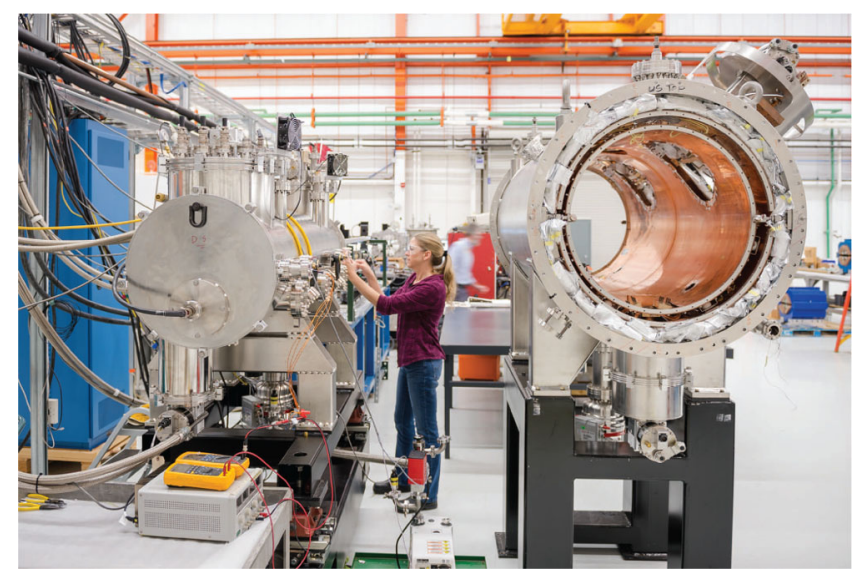

FIG. 19. Side by side comparison of the 1 st and 2 nd generation cryostats.

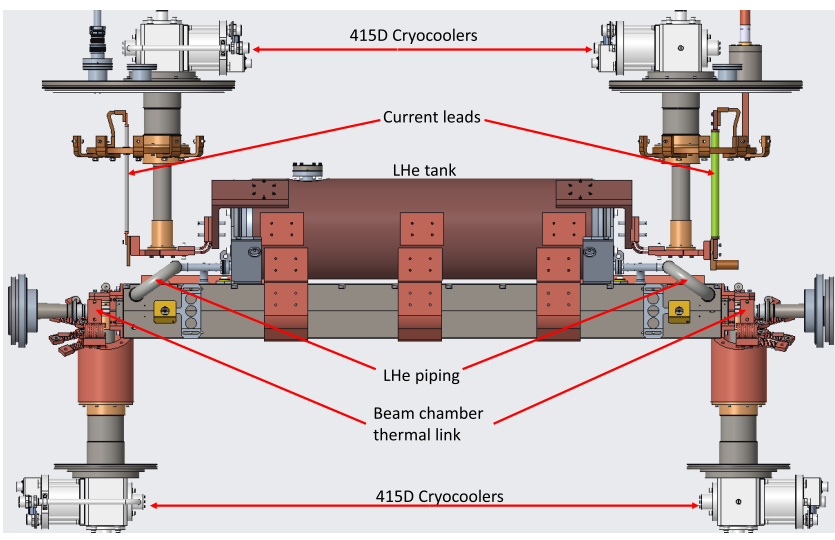

FIG. 20. Cold mass and cryocoolers of the HSCU highlighting the main components of the system. Not shown is the thermal radiation shield and vacuum vessel.

cold mass position using a newly developed 2-D laser scanning method [22]. The same philosophy of thermally isolating the beam chamber from the magnet to allow the beam chamber to run at an elevated temperature without affecting the magnet operation was retained. A complete description of the 2nd-generation cryostat design has been previously published $[13,23]$.

Figure 20 shows the cold mass and cryocoolers of the HSCU cryostat. All of the cryocooler 1st stages are connected to the thermal radiation shield which is not shown. The 1st stages also provide cooling for the HTS current leads and the beam chamber. All of the 2nd stages are thermally connected to the LHe tank for the magnet cooling circuit. The magnet/mold is cooled via LHe through piping between the mold and the LHe tank as well as copper thermal links.

\section{Predicted heat loads}

The analysis of anticipated heat loads on the superconducting magnet is crucial for the design of the HSCU cooling circuit. The total heat load in the superconducting undulator includes both static heat loads, which are typical for superconducting magnets, and the heat load from the electron beam. The beam heat load includes heating of the HSCU vacuum chamber by beam-induced image currents, synchrotron radiation generated in upstream dipole magnets, wakefield effects, particle losses, and, potentially, electron cloud-induced multipacting (the latter has not been observed at APS).

Unlike the planar SCU devices where any beam-induced power absorbed by the beam chamber is periodically intercepted by thermal intercepts connected to the beam chamber along the entire length of the beam chamber, the nature of the HSCU magnet only allows for thermal intercepts at the ends of the chamber outside of the magnet. This is evident in Figs. 12 and 20 where the beam chamber is fully enveloped by the magnet and access is only 
available at the end. Another significant difference between the HSCU beam chamber and the planar SCU beam chambers is the beam chamber aperture. In HSCU the horizontal aperture of the beam chamber is $26 \mathrm{~mm}$ compared to $53 \mathrm{~mm}$ in the planar SCUs. A photon absorber installed upstream of the HSCU masks synchrotron radiation from being deposited on the stainless steel (SS) transitions between the room temperature flange and the aluminum beam chamber. However, the absorber cannot fully shield the aluminum (Al) portion of the HSCU chamber from in-plane, high-energy synchrotron photons. For this reason, synchrotron radiation heating is the dominant source of the beam-induced heat load. Prior to HSCU installation, a test chamber with identical aperture and cross section was installed in the APS storage ring.

Similar to the planar SCU chambers, calibrated heater wires were used to calibrate applied power with temperature. Beam heating was analyzed for the test chamber, assuming 24 bunches; the results are shown in Table II. For synchrotron radiation, it is assumed that all incident photons are absorbed. Because the SS transition sections are shielded, only the radiation power on the $\mathrm{Al}$ part of the chamber was included. For the resistive wall power due to image currents, room temperature resistivities of $3.2 \times$ $10^{-8} \Omega \mathrm{m}$ for $\mathrm{Al}$ and $77.7 \times 10^{-8} \Omega \mathrm{m}$ for SS were used. Thermal diffusion and conductivity differences were not included in the total. The temperature of the test chamber was then measured with 24 uniformly filled bunches. The heat load from the beam was found to be in reasonable agreement with predictions. The total predicted heat load was $45 \mathrm{~W}$ at $100 \mathrm{~mA}$, while the measurements gave $30 \mathrm{~W}$ to $40 \mathrm{~W}$, using the heater calibration. Details of the calculations and the measurements can be found in [24]. For the cold HSCU chamber, the synchrotron radiation heat load is the same, but the resistive heat load is lower because the conductivity at low temperature is reduced. The resistive losses scale like $I^{2} \sqrt{\rho(T)} L / a$, where $I$ is the beam current, $\rho(T)$ is the resistivity, $T$ is the temperature, $L$ is the length of the chamber, and $a$ is the average full height of the beam chamber aperture. The resistivity can further be expressed as $\rho(T)=\rho(300 K) / R(T)$, where resistivity at room temperature $\rho(300 K)$ was given above, and $R(T) \geq 1$ is the ratio of the resistivity at room temperature to the resistivity at temperature $T$. The temperature is not

TABLE II. Predicted beam-induced heat loads on the HSCU test chamber at $300 \mathrm{~K}$.

\begin{tabular}{lcccc}
\hline \hline $\begin{array}{l}\text { Beam } \\
\text { current } \\
(\mathrm{mA})\end{array}$ & $\begin{array}{c}\text { Synchrotron } \\
\text { radiation } \\
(\mathrm{W})\end{array}$ & $\begin{array}{c}\text { Resistive } \\
\text { wall (Al) } \\
(\mathrm{W})\end{array}$ & $\begin{array}{c}\text { Resistive } \\
\text { wall }(\mathrm{SS}) \\
(\mathrm{W})\end{array}$ & $\begin{array}{c}\text { Total } \\
\text { power } \\
(\mathrm{W})\end{array}$ \\
\hline 25 & 7.2 & 0.8 & 0.2 & 8.2 \\
50 & 14.4 & 3.2 & 0.9 & 18.5 \\
100 & 28.9 & 13 & 3.5 & 45.4 \\
\hline \hline
\end{tabular}

constant over the length of the HSCU vacuum chamber, approximately ranging from $40 \mathrm{~K}$ at the ends to $120 \mathrm{~K}$ at the center with $R$ varying between 10 and 3.2. Therefore, the assumptions in Table II regarding resistive losses are conservative.

In order to incorporate the beam chamber heat load into the overall cryogenic design, an FEA model was created in ANSYS [23,25]. Many aspects of the model had been benchmarked against the performance of the 1st-generation cryostats, and the same approach was used when modeling the 2nd-generation cryostat design. As previously stated, the 2nd-generation cryostat contains two thermal stages provide by four Sumitomo RDK-415D cryocoolers. The 1 st stages of all four cryocoolers are tied together and provide cooling for the thermal radiation shield, beaminduced heat loads, and any conduction paths from room temperature such as current leads, instrumentation, and the cold mass supports. All four 2nd stages are connected to the copper surface of the LHe tank and are responsible for cooling the magnet, LHe tank, intercepting conduction heating from the HTS leads and instrumentation, and thermal radiation. The anticipated heat loads are shown in Table III for three different cases for both cooling circuits. Case 1 is static, Case 2 is the additional beaminduced heat load reduced slightly to account for the cold beam chamber, and Case 3 is the additional heat load when powering the magnet at $500 \mathrm{~A}$.

With the expected heat loads given in Table III, the capacity of the four cryocoolers is sufficient to provide cooling in all modes of operation. Combined, the four 1st stages provide $180 \mathrm{~W}$ at $50 \mathrm{~K}$ and the 2 nd stages are rated at $1.5 \mathrm{~W}$ at $4.2 \mathrm{~K}$. Since the total heat load is lower than the capacity, the actual operating temperature can be predicted from the load map of the cryocooler 1st stage to be approximately $40 \mathrm{~K}$. As with the 1st-generation cryostat, the pressure in the LHe tank is regulated at 760 Torr by powering a heater that maintains the LHe tank and magnets at $4.2 \mathrm{~K}$. We refer to the required heater power as the excess capacity of the cryocooler 2nd stages. Based on previous experience, we know there is a gradient across the thermal links and their contact resistances to the 2nd stages, and the expected excess capacity for Case 3 from the model is $1 \mathrm{~W}$.

As mentioned earlier, the beam chamber is cooled only at the ends where it is accessible outside of the magnet. Inside the magnet there is a $0.5 \mathrm{~mm}$ vacuum gap between the beam chamber and the cold magnet. The gap is maintained by low heat leak Torlon pins at several locations along the

TABLE III. Predicted heat loads on the HSCU cooling circuits.

\begin{tabular}{lcccc}
\hline \hline $\begin{array}{l}\text { Cooling } \\
\text { circuit }\end{array}$ & $\begin{array}{c}\text { Case 1 } \\
\text { Static }(\mathrm{W})\end{array}$ & $\begin{array}{c}\text { Case 2 Beam } \\
\text { induced }(\mathrm{W})\end{array}$ & $\begin{array}{c}\text { Case 3 Joule } \\
\text { heat }(\mathrm{W})\end{array}$ & $\begin{array}{c}\text { Total } \\
(\mathrm{W})\end{array}$ \\
\hline $1^{\text {st }}$ Stage & 43.5 & 40 & 22.5 & 106 \\
$2^{\text {nd }}$ Stage & 0.5 & 0.18 & 0.13 & 0.81 \\
\hline \hline
\end{tabular}




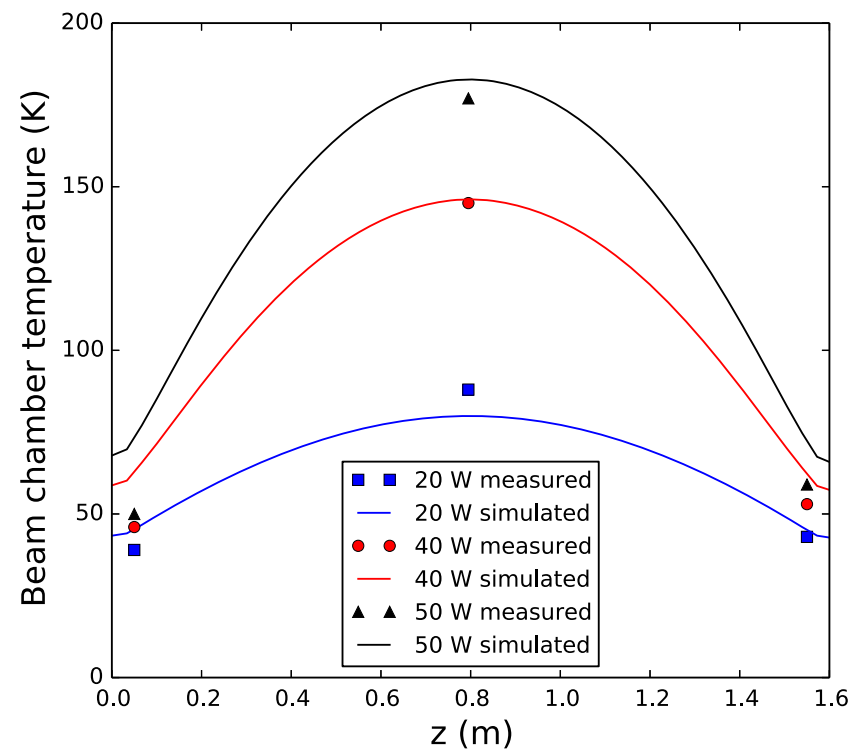

FIG. 21. Simulated and measured HSCU Al beam chamber temperature profile under different heat loads.

length of the chamber. With this configuration the beam chamber is expected to be considerably warmer in the center under operating conditions in the storage ring. ANSYS FEA simulation results concluded that at a beam-induced heat load of $40 \mathrm{~W}$, the temperature at the center of the chamber could reach $140 \mathrm{~K}$. The profile of the chamber temperature under different heat loads was simulated, as seen in Fig. 21.

\section{COLD TEST RESULTS}

\section{A. Cryogenic testing}

Several engineering cooldowns were conducted to evaluate the performance of the 2nd-generation cryostat. Modifications were made between each cooldown to address various heat loads that exceeded expectations, such as thermal radiation from room temperature to $4 \mathrm{~K}$ and conduction heat paths through the cold mass support rods. Temperatures recorded during a typical $36 \mathrm{~h}$ cooldown are shown in Fig. 22. During the cooldown process the pressure in the LHe tank is maintained at or above atmospheric pressure using helium gas. The temperature of the LHe tank and magnet go below $6 \mathrm{~K}$ after $36 \mathrm{~h}$, at which point the internal LHe tank is filled with $15 \mathrm{~L}$ of $\mathrm{LHe}$ from a $60 \mathrm{~L}$ dewar, bringing the temperature of the LHe tank and magnet to $4.2 \mathrm{~K}$. Although not directly measured, a small quantity of LHe is vented during the transfer process and excess LHe remains in the dewar. After the transfer of LHe, the system operates in a closed loop and an internal heater is used to maintain the pressure in the LHe tank at or above atmospheric pressure. No LHe is lost during operation or during a quench.

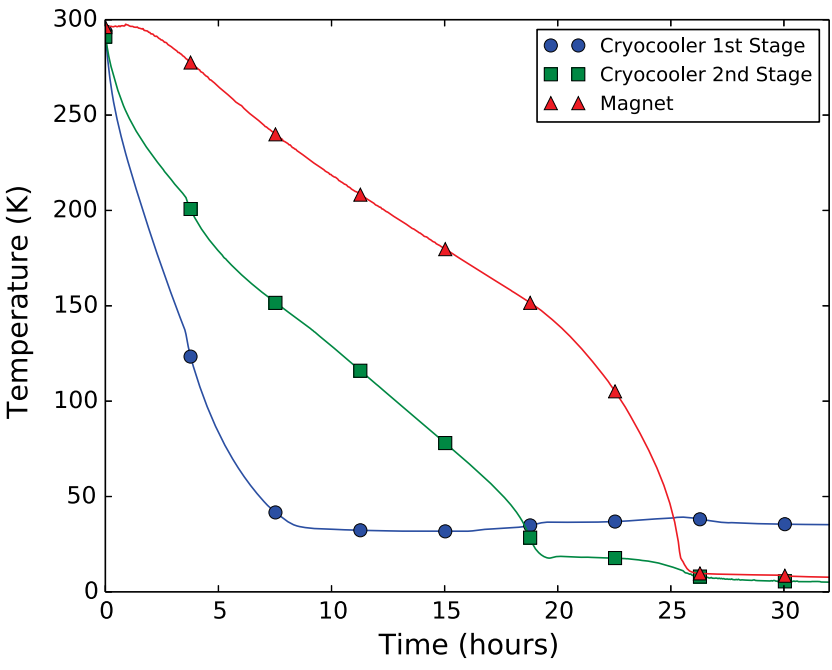

FIG. 22. Representative temperatures of HSCU components during the cool down process. The magnet temperatures reach $6 \mathrm{~K}$ after $36 \mathrm{~h}$ which enables the transfer of LHe to bring the temperatures to the operating value of $4.2 \mathrm{~K}$.

During one of the engineering cooldowns, the chamber heat load due to the electron beam was simulated by powering an electric heating element embedded into channels of the $\mathrm{Al}$ beam chamber. Data were collected with and without the magnet powered to $500 \mathrm{~A}$. As expected, the temperature of the beam chamber increased, with the warmest temperature at the center, but the magnet temperature was stable. Also monitored was the excess capacity as determined by the required heater power to maintain the LHe tank pressure at 760 Torr. Results of the test are listed in Table IV. Note that the chamber center temperature agrees well with the simulation data in Fig. 21. Even with $50 \mathrm{~W}$ applied to the beam chamber, there is less than $0.4 \mathrm{~W}$ transmitted to the magnet cooling circuit, demonstrating excellent thermal isolation of the superconducting magnet from the beam chamber.

Results listed in Table III are not of the final configuration because the beam chamber end flanges and stainless steel transitions had not been welded on yet, which slightly reduces the conduction heat leak from room temperature. Before the final assembly, the beam chamber

TABLE IV. Observed temperatures of the beam chamber and the magnet during the beam heat load simulation test.

\begin{tabular}{lccc}
\hline \hline $\begin{array}{l}\text { Applied } \\
\text { power (W) }\end{array}$ & $\begin{array}{c}\text { Magnet } \\
\text { current (A) }\end{array}$ & $\begin{array}{c}\text { Chamber center } \\
\text { temperature (K) }\end{array}$ & $\begin{array}{c}\text { Excess } \\
\text { capacity (W) }\end{array}$ \\
\hline 0 & 0 & 33.4 & 0.96 \\
0 & 500 & 33.4 & 0.90 \\
20 & 500 & 88 & 0.80 \\
40 & 500 & 145 & 0.67 \\
50 & 500 & 177 & 0.57 \\
\hline \hline
\end{tabular}




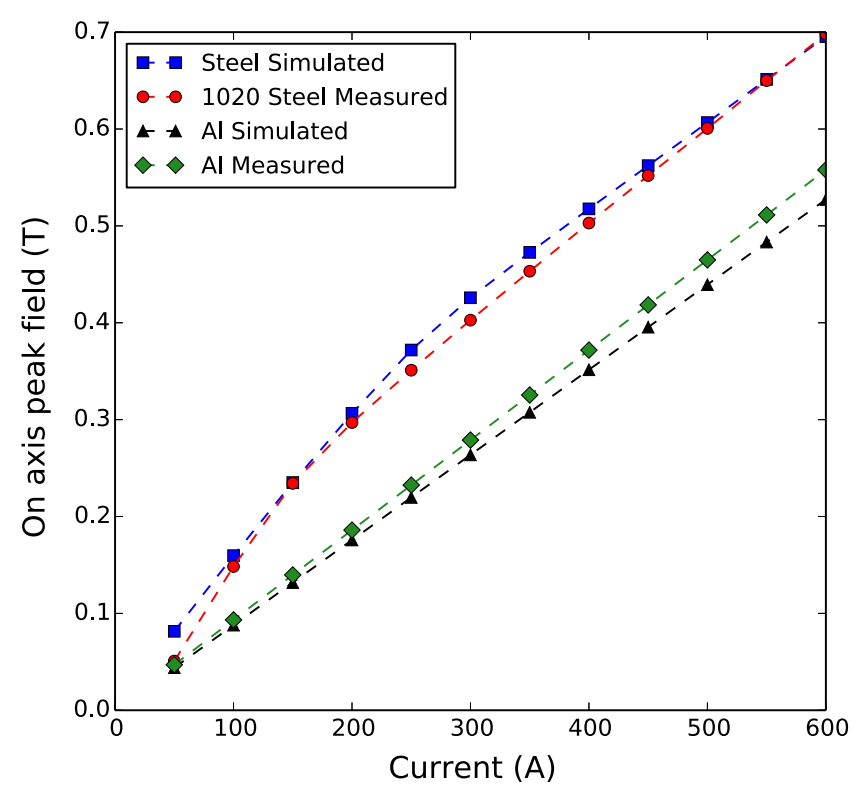

FIG. 23. Excitation curves of the 20-mm-period short prototype HSCU magnets.

was removed for cleaning and the heating elements were removed.

\section{B. Magnet testing \\ 1. Prototype magnets}

The first prototype magnets measured were the previously described $0.3 \mathrm{~m} \mathrm{Al}$ and 1020 steel magnets with a $20 \mathrm{~mm}$ period and a winding bore of $15 \mathrm{~mm}$. The main purpose of these prototypes was to verify the winding scheme; however, they were epoxy-impregnated and tested in a vertical LHe bath cryostat equipped with the linear translation stage that guides the Hall probe on axis of the tested undulator. Of note to mention here is that the magnets required little to no coil training. The $\mathrm{Al}$ magnet reached $640 \mathrm{~A}$ after only one quench, which is $94 \%$ of the critical current expected from simulations. After three quenches the steel magnet reached $612 \mathrm{~A}$, which is $99 \%$ of the critical current expected based on simulations. Hall probe measurements were also performed to compare the model data with measured data. Excitation curves of both $20 \mathrm{~mm}$ prototype magnets are shown in Fig. 23. Predicted values typically agree with the measured values to within $6 \%$. Steel poles provide a gain of $\sim 25 \%$ at currents above $300 \mathrm{~A}$.

When observing the absolute value of the field peaks along the length of both prototypes a clear step is noticeable, as seen in Fig. 24. This indicates there was a machining error as a result of the fixturing used during manufacturing. Simulations indicated that the change in the winding diameter of both magnets was around $100 \mu \mathrm{m}$.

Following the short-period prototypes, a prototype magnet close to the geometry of the final magnet was tested in

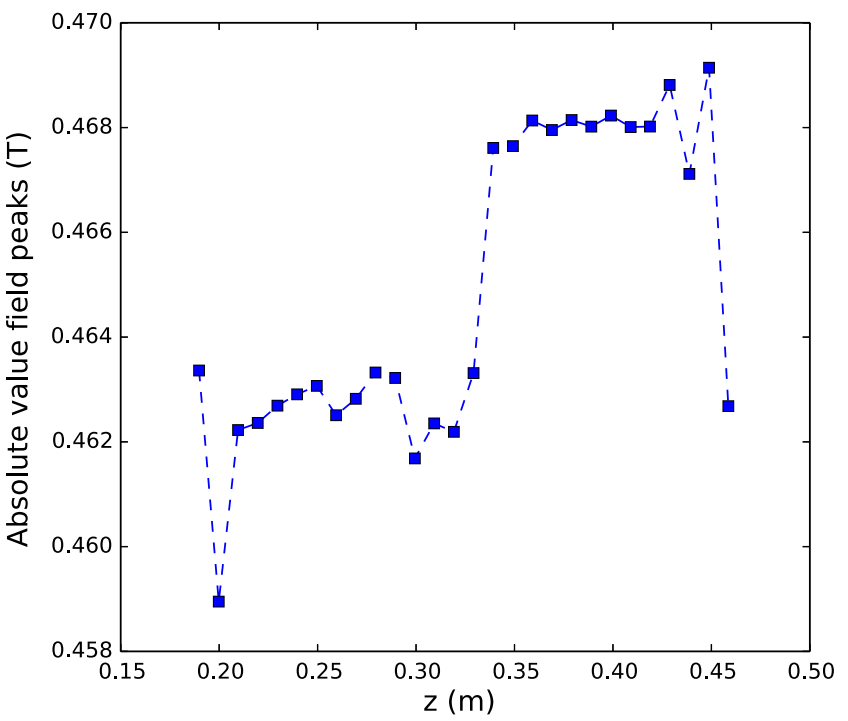

FIG. 24. Absolute value of the magnetic field peaks of the $20 \mathrm{~mm}$-period $\mathrm{Al}$ prototype. The step represents a $100 \mu \mathrm{m}$ change in the winding bore of the mandrel that was found on both prototypes.

the LHe bath cryostat. The magnet was $0.3 \mathrm{~m}$ long with a period of $31.5 \mathrm{~mm}$. As previously described, due to the dimensions of the mandrel there were 115 conductors in each helical coil pack, not the 138 that was planned for the final assembly. This prototype was first tested inside the 1020 steel mold; then the magnet was removed from the mold and the tests were repeated.

Due to the reduced number of turns, the magnet was expected to reach a field of $0.41 \mathrm{~T}$ at a current of $500 \mathrm{~A}$ to 550 A. Initial coil training was performed and after the sixth quench the magnet reached $500 \mathrm{~A}$. After a thermal cycle it reached $500 \mathrm{~A}$ on the first quench. After a total of 50 quenches over two thermal cycles, the magnet reached a maximum current of $678 \mathrm{~A}$, which is $99 \%$ of the expected critical current from the model.

Comparing the measurement data between the two tests indicated the steel mold increased the on-axis field by almost $8 \%$ in the expected operating range. Shown in Fig. 25 are the excitation curves of the prototype magnet with and without the mold. Table $\mathrm{V}$ summarizes the prototype magnet testing.

Similar to the short-period prototypes, a step change in the winding diameter at the center of the mandrel can be seen when observing the absolute value of the field peaks from a Hall probe scan, see Fig. 26. The step can be attributed to a change in the mandrel support fixturing during machining, see Fig. 9.

Integrating the Hall probe data gave an indication of the required field integral strength of the corrector magnets. The Hall probe field scans and the 1st field integrals are shown in Fig. 27. The magnetic field was measured in orthogonal planes by rotating the Hall probe $90^{\circ}$, and it can 


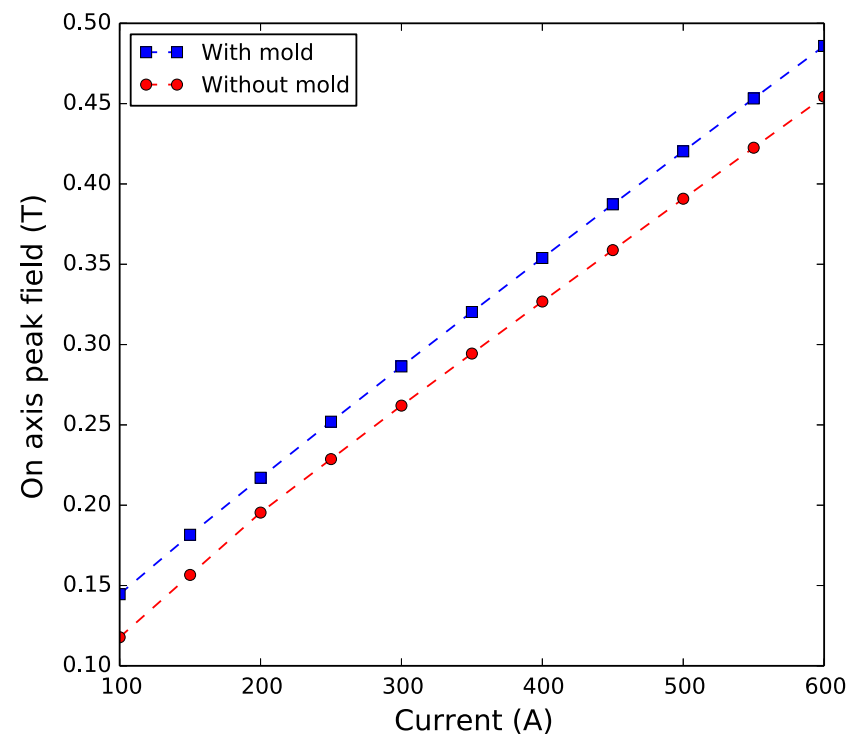

FIG. 25. The on-axis peak field achieved with the $31.5 \mathrm{~mm}$ short prototype HSCU with and without the 1020 steel mold.

be seen that the phase difference between the two scans is $90^{\circ}$. As can be seen by the integrated data, the required field strength of the correctors could be as much as $3000 \mu \mathrm{T} \mathrm{m}$.

\section{Full length magnet}

Upon completion of winding and epoxy impregnation, the $1.2 \mathrm{~m}$ full-length magnet, consisting of 38.5 full periods with two periods at each end devoted to the conductor turn around geometry, was first tested in the vertical LHe bath cryostat. Following assembly into the 2nd-generation cryostat, the magnet was measured using the SCU horizontal magnetic measurement system at the APS [26].

Each time the magnet was cooled down, coil training was performed. The first training occurred in the LHe bath cryostat and the magnet reached a current of $500 \mathrm{~A}$ after 20 quenches. Compared to the six quenches required for the $0.3 \mathrm{~m}$ prototype magnet to reach $500 \mathrm{~A}$, the required number of training quenches appears to scale with the length of the device. Similar behavior was observed with the planar SCUs [10]. At this point preliminary Hall probe field scans were performed with coil training resuming afterward. In all, there were 58 training quenches and the maximum current reached was $557 \mathrm{~A}$ before the $\mathrm{LHe}$

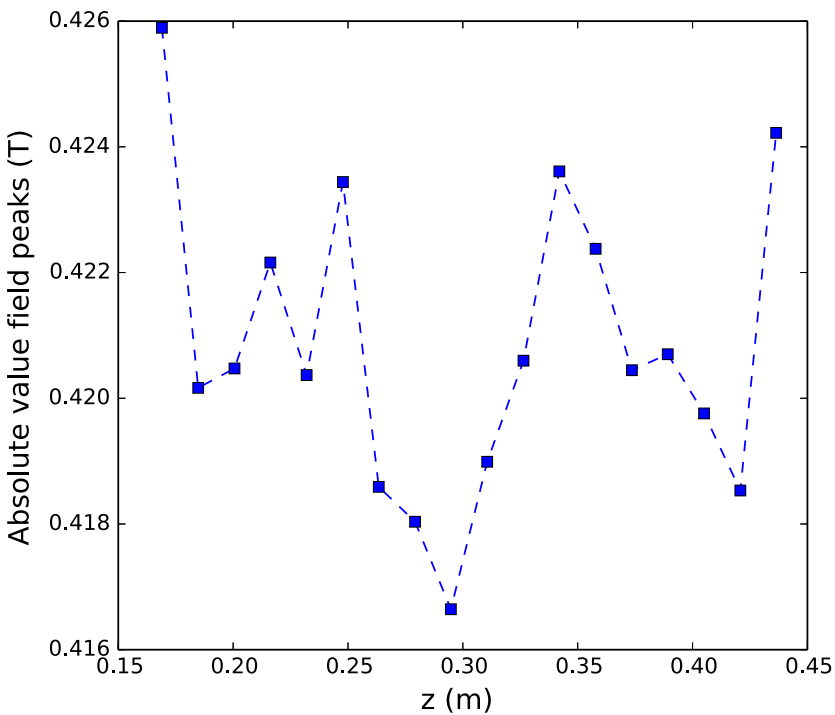

FIG. 26. Absolute value of the magnetic field peaks of the $31.5 \mathrm{~mm}$ period prototype.

supply was exhausted, see Fig. 28. According to the simulation, the critical current was determined to be $660 \mathrm{~A}$. In the plot, it is apparent that the quench current was still increasing at the conclusion of training. After each subsequent cooldown the magnet was retrained.

The first two cooldowns in the horizontal cryostat required five quenches to reach $500 \mathrm{~A}$, four subsequent cooldowns required no more than two quenches to reach $500 \mathrm{~A}$, with some requiring zero. Although further training of the magnet was lower priority than the magnetic measurements, some training was performed. The maximum current reached in subsequent training in the horizontal cryostat was $596 \mathrm{~A}$, giving a comfortable margin with the expected operating current below $500 \mathrm{~A}$.

Once the final assembly was completed, the HSCU was characterized magnetically using three methods: scanning Hall probe, rotating coil, and pulsed wire [27]. The goals of the measurement plan were to measure the peak field as a function of current, build a feed forward look-up table to power the end correctors as a function of the main current, and measure any multipole components of the magnet. Due to the complex nature of the HSCU magnetic field, all three methods were used iteratively until confidence in the measurements was reached.

TABLE V. Summary table of the prototype magnets.

\begin{tabular}{lccccccc}
\hline \hline Period $(\mathrm{mm})$ & $\begin{array}{c}\text { Winding } \\
\text { diameter }(\mathrm{mm})\end{array}$ & Turns & $\begin{array}{c}\text { Core } \\
\text { material }\end{array}$ & $\begin{array}{c}\text { Mold } \\
\text { material }\end{array}$ & $I_{\max }(\mathrm{A})$ & $\begin{array}{c}I_{\mathrm{c}} \text { from } \\
\text { model@4.2 K (A) }\end{array}$ & $\begin{array}{c}B_{\text {peak }} \text { at } \\
0.8 I_{\mathrm{c}}(\mathrm{T})\end{array}$ \\
\hline 20 & 15 & 53 & $\mathrm{Al}$ & $\mathrm{Al}$ & 640 & 680 & 0.51 \\
20 & 15 & 53 & Steel & $\mathrm{Al}$ & 612 & 618 & 0.60 \\
31.5 & 31 & 115 & Steel & Steel & 678 & 685 & 0.45 \\
31.5 & 31 & 115 & Steel & None & NA & NA & 0.42 \\
\hline \hline
\end{tabular}



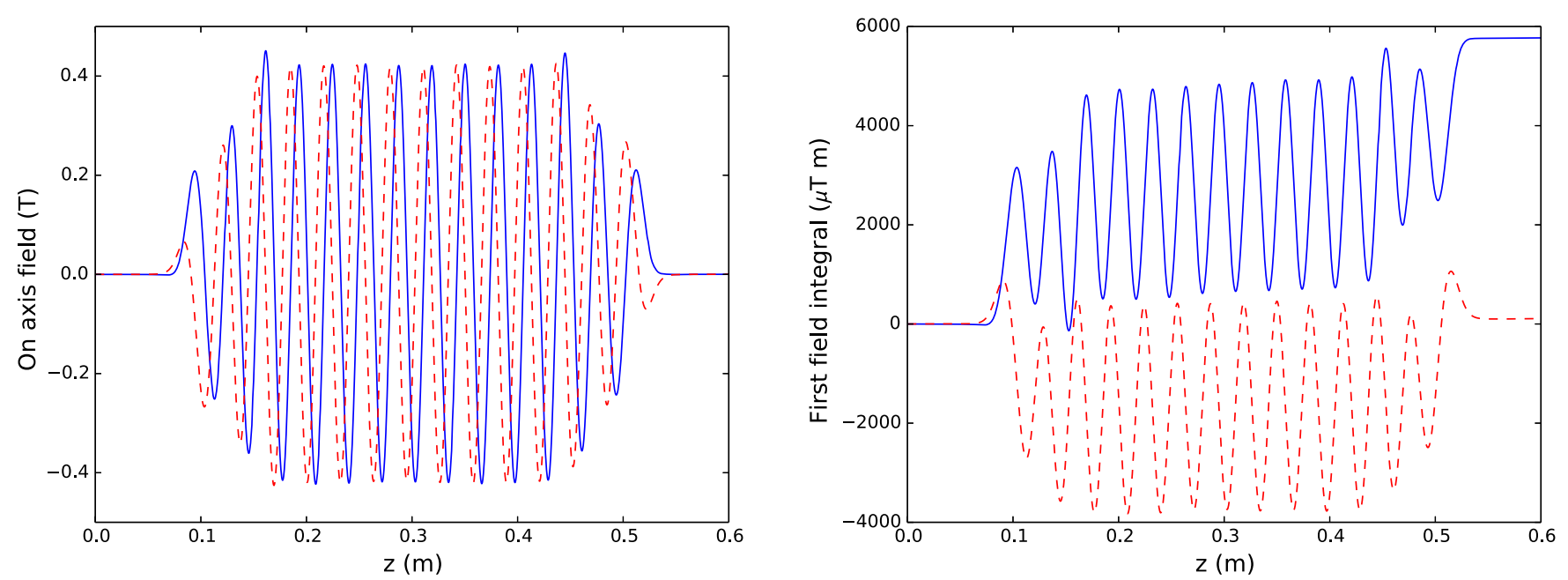

FIG. 27. Left: Orthogonal Hall probe field scans of the $31.5 \mathrm{~mm}$ prototype HSCU. Right: Integrated Hall probe data.

The excitation curve of the magnet is shown in Fig. 29. An effective field of $0.41 \mathrm{~T}$ was reached at a current of 450 A, satisfying the operational requirement. The measured field was $\sim 4 \%$ greater than the peak field predicted by the model for most currents.

Using a three-axis Senis [28] Hall probe, the horizontal, vertical, and longitudinal magnetic field components were measured. A typical field profile showing all three field components is shown in Fig. 30 for a 500 A scan.

At the operating current of $450 \mathrm{~A}$, the analysis of the measured field at the maxima and minima gives the average peak field value of $0.4092 \mathrm{~T}$ with a standard deviation of $0.0026 \mathrm{~T}$ and a maximum peak to peak deviation of $0.0188 \mathrm{~T}$. The half period length is calculated as $15.72 \mathrm{~mm}$ with a standard deviation of $0.020 \mathrm{~mm}$ and a peak to peak deviation of $0.15 \mathrm{~mm}$. The large peak to peak deviations are due to the

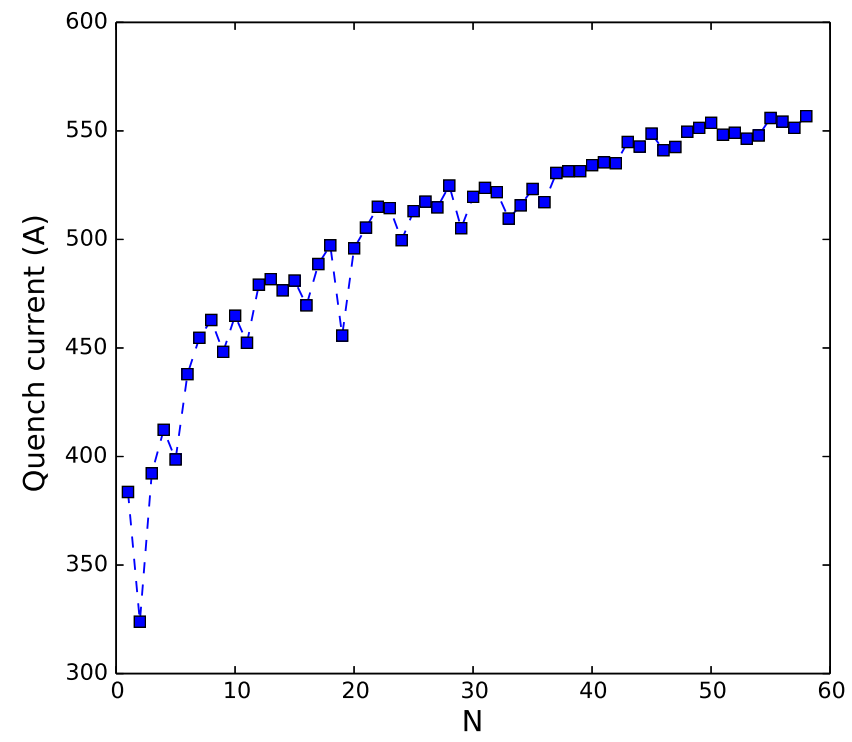

FIG. 28. Quench currents during training of the HSCU in the LHe bath cryostat. two regions near $-0.1 \mathrm{~m}$ and $-0.3 \mathrm{~m}$ where the magnitude of the field peak and half period length vary the most. The phase errors shown in Fig. 31 were calculated from the Hall probe measurements after omitting data from seven poles from each end of the undulator.

Also, at a current of $450 \mathrm{~A}$, the measured phase error for the vertical and horizontal field measurements is about $8.2^{\circ} \mathrm{rms}$ and $9.3^{\circ} \mathrm{rms}$, respectively. These values exceed $8^{\circ} \mathrm{rms}$ specifications but still are acceptable for one ID to be installed on the ring. Preliminary analysis and comparison of data obtained from CMM measurements of helical groove profile and peak field distribution along the length of the HSCU indicate that the excessive magnitude of phase errors can be attributed to the deviation from specified tolerances in the machining of the winding mandrel. Shown in Fig. 32 are the absolute values of the vertical field peaks

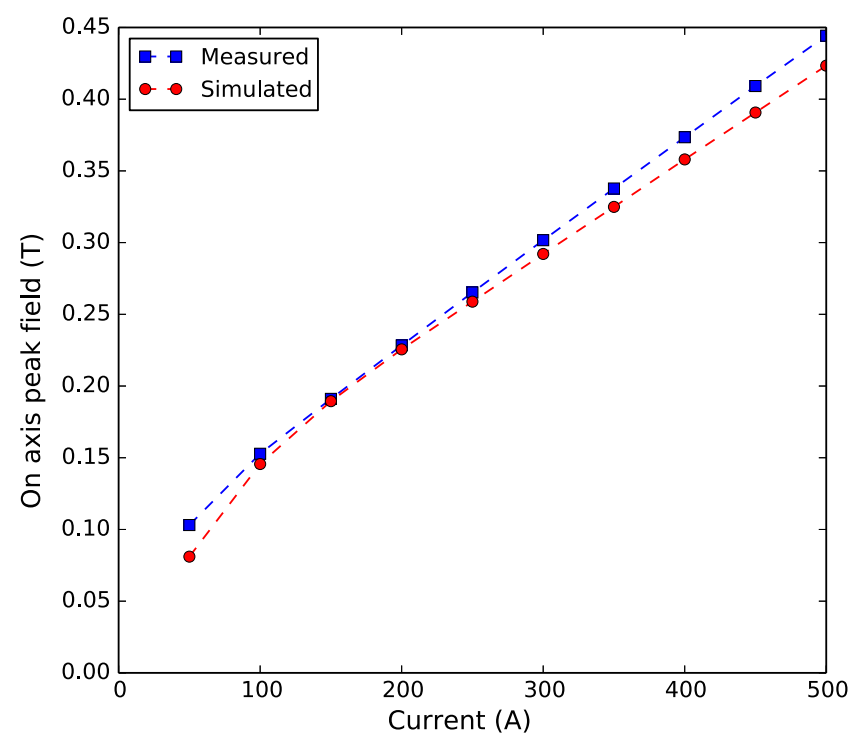

FIG. 29. Measured and predicted magnet excitation curves. The operating value of $0.41 \mathrm{~T}$ is reached at $450 \mathrm{~A}$. 


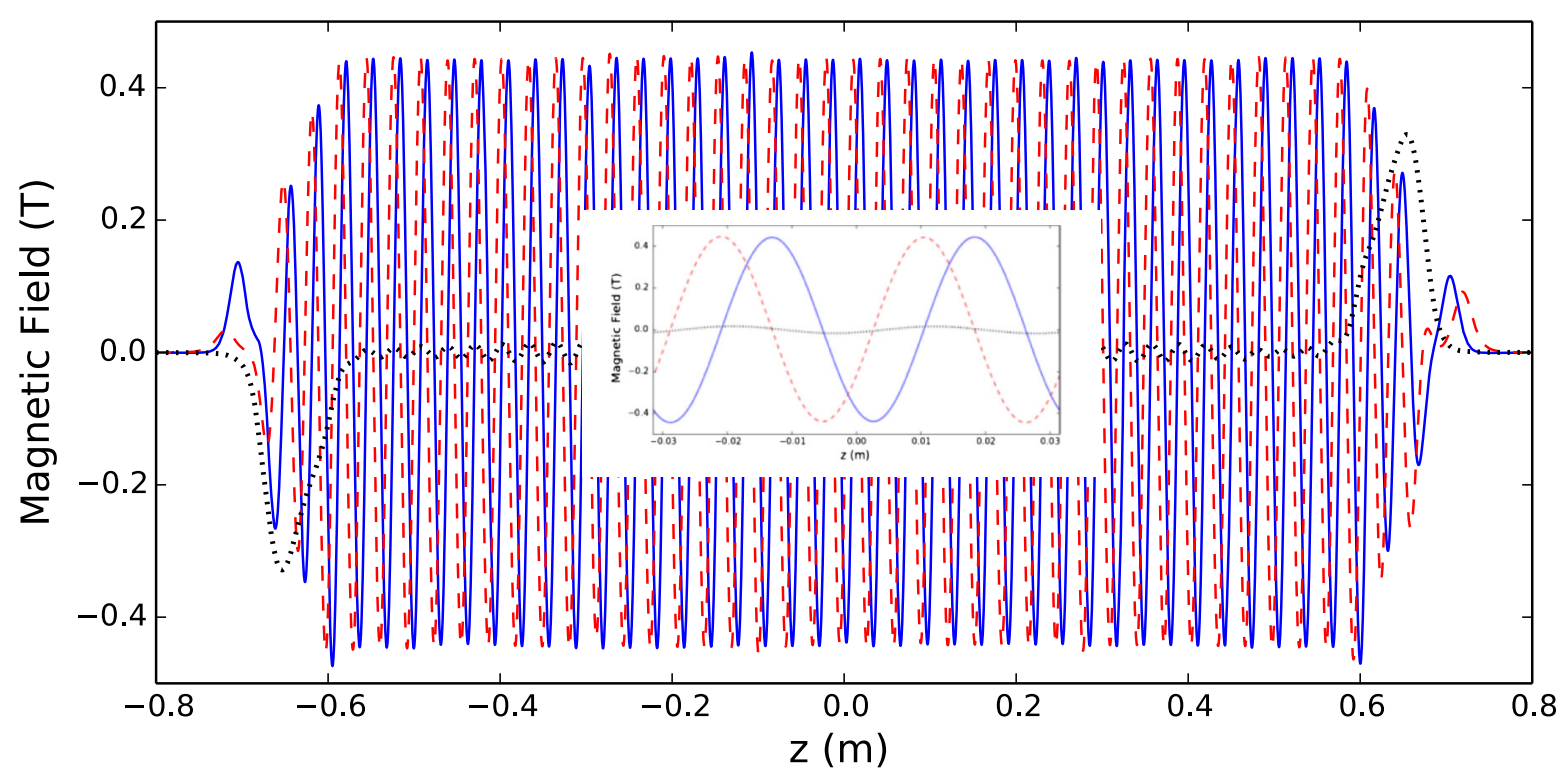

FIG. 30. Measured undulator field profile showing all three field components with a magnet current of 500 A. Two periods of the scan in the center of the HSCU are shown in the inset.

for a Hall probe field scan at $450 \mathrm{~A}$. The more pronounced peaks are in the regions where the pole is wider or narrower than the nominal dimension, and from $\pm 0.2 \mathrm{~m}$, a taper in the field can be observed.

Measurements of the 1st and 2nd field integrals were accomplished by alternating between the rotating coil and pulsed wire methods. A feed forward lookup table to control the corrector power supplies was developed once the appropriate correction current was determined. Due to the measurement system guide tube through the beam chamber aperture, we were restricted to using a $2 \mathrm{~mm}$ diameter rotating coil for the measurements to reduce the

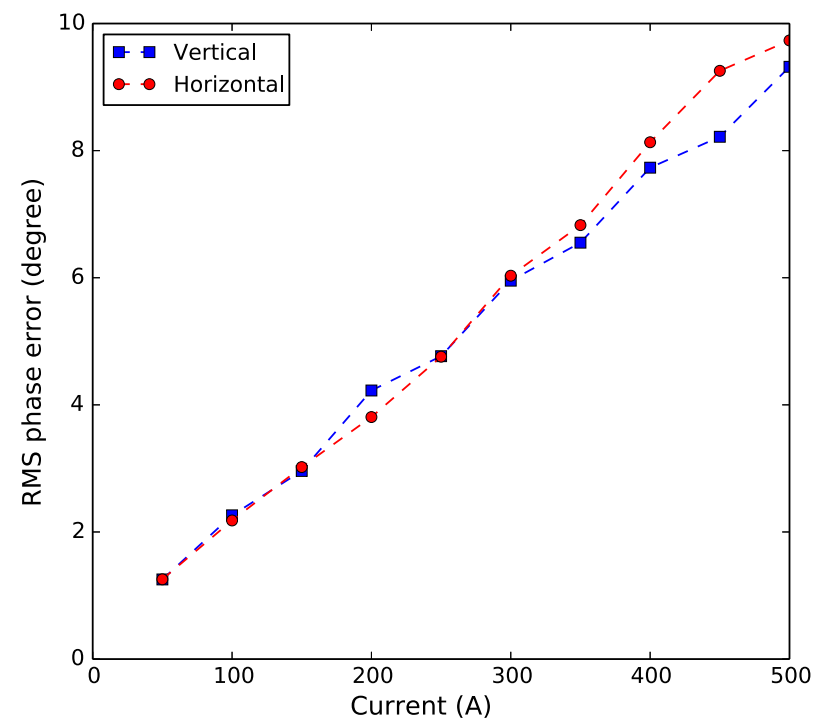

FIG. 31. Vertical and horizontal measured phase errors as a function of magnet current. possibility of interference between the measurement coil and guide tube. Also, the position of the coil or pulsed wire inside the aperture had an effect on the measured field integrals due to the nature of the helical field. Alternating between the two techniques allowed us to establish the correct measurement position to be close to the center of the magnet. Table VI shows the amount of field correction needed to minimize the horizontal and vertical field integrals.

At currents greater than 350 A there was not enough correction available on the upstream vertical field correctors, causing the vertical 2nd field integral to exceed the APS storage ring requirements. There were three reasons that the correctors were not sufficient: first, the amount of required correction was greater than expected; second, the vertical correctors were mounted closer to the mold than the horizontal correctors, causing the field to be attenuated; and third, the current feedthroughs used limited the power to the

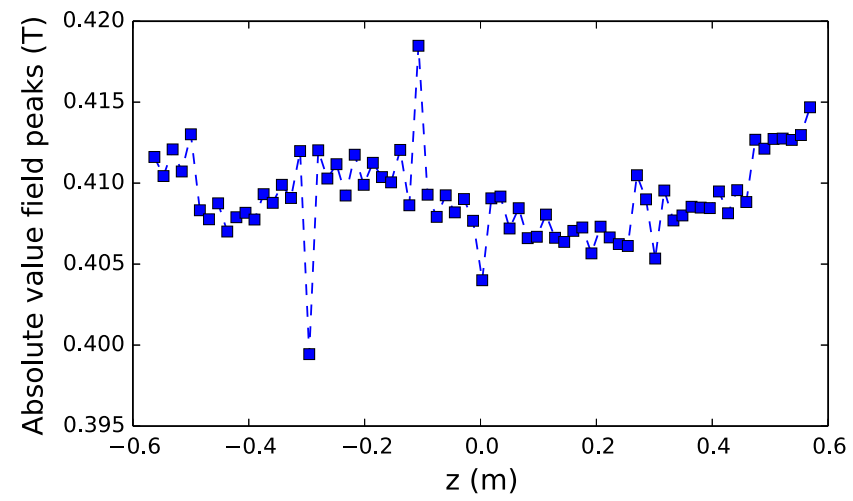

FIG. 32. Vertical field peaks of the HSCU at 450 A. 
TABLE VI. Vertical and horizontal field correction necessary to minimize the field integrals.

\begin{tabular}{lcccc}
\hline \hline $\begin{array}{l}\text { Main } \\
\text { current } \\
(\mathrm{A})\end{array}$ & $\begin{array}{c}\text { Upstream } \\
\text { vertical } \\
(\mu \mathrm{T}-\mathrm{m})\end{array}$ & $\begin{array}{c}\text { Upstream } \\
\text { horizontal } \\
(\mu \mathrm{T}-\mathrm{m})\end{array}$ & $\begin{array}{c}\text { Downstream } \\
\text { vertical } \\
(\mu \mathrm{T}-\mathrm{m})\end{array}$ & $\begin{array}{c}\text { Downstream } \\
\text { horizontal } \\
(\mu \mathrm{T}-\mathrm{m})\end{array}$ \\
\hline 50 & 1020 & 595 & 972 & 587 \\
100 & 1560 & 510 & 1176 & 1063 \\
150 & 2160 & 383 & 1338 & 1632 \\
200 & 2670 & 493 & 1704 & 2049 \\
250 & 3108 & 638 & 1974 & 2295 \\
300 & 3390 & 723 & 2208 & 2508 \\
350 & 3600 & 744 & 2280 & 2550 \\
400 & $3720^{\mathrm{a}}$ & 744 & 2460 & 2669 \\
450 & $3720^{\mathrm{a}}$ & 706 & 2700 & 2814 \\
500 & $3720^{\mathrm{a}}$ & 638 & 3012 & 3069 \\
\hline \hline
\end{tabular}

${ }^{\mathrm{a}}$ Not enough correction, see text for explanation.

correctors. To alleviate this issue during operation in the storage ring, an additional corrector was installed upstream of the HSCU, outside of the cryostat. Characterization of the multipole components were performed by measuring with the rotating coil. Measurements of the 1 st field integral were made along the horizontal axis of the HSCU in $0.5 \mathrm{~mm}$ increments over a range of $\pm 5 \mathrm{~mm}$. A power series fit of the integral data versus horizontal position was used to determine the multipole components shown in Table VII.

Analysis of these data confirmed that the measured multipoles would have a minor impact on storage ring operations [21].

\section{HSCU OPERATING EXPERIENCE}

\section{A. Commissioning}

Integration of the HSCU into the APS storage ring presents a unique challenge, given the small horizontal aperture of the vacuum chamber. The HSCU vacuum chamber is the smallest horizontal aperture in the APS storage ring: $\pm 13 \mathrm{~mm}$. Even though the device parameters were optimized for the horizontal beta function of the electron beam of $10 \mathrm{~m}$, to make the acceptance of the HSCU vacuum chamber larger than the two next-smallest acceptances in the ring, the horizontal beta function at the device had to be reduced from $20 \mathrm{~m}$ to $9 \mathrm{~m}$ instead of

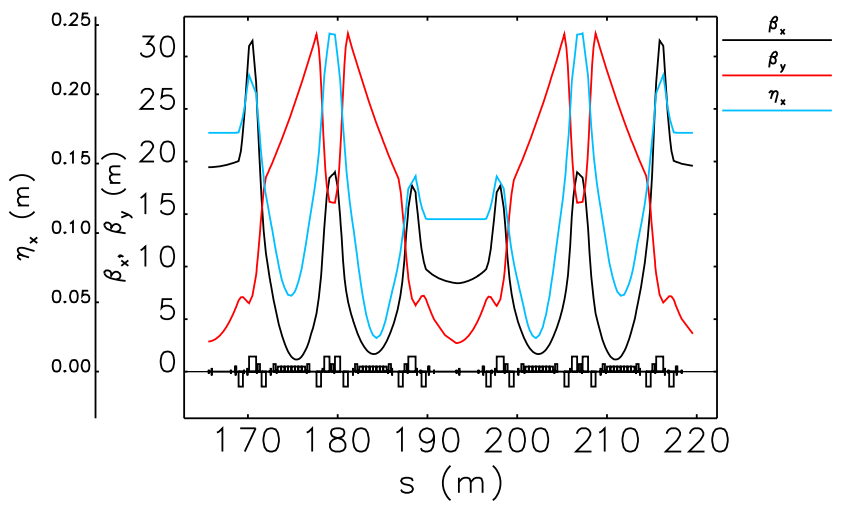

FIG. 33. Reduced lattice functions at the HSCU location. Two sectors are shown. Middle of the plot shows the HSCU location, while the left and right sides of the plot show the standard APS ID straight sections.

originally intended $10 \mathrm{~m}$. The difference in beta function values was considered negligible for the device performance. Multiobjective genetic optimization was used to design the lattice without impact on lifetime or injection efficiency. The lattice was first tested before any hardware modifications. Figure 33 shows the modified lattice functions at the HSCU location.

The HSCU cooling system was designed to handle the expected vacuum chamber heating, as confirmed by the test chamber measurements. However, after injecting the first electron beam, unexpected heating of the magnet coils was observed, even though the vacuum chamber temperature was consistent with the predicted incident power. The magnet coils exceeded $6 \mathrm{~K}$ when the stored beam current reached $80 \mathrm{~mA}$ ( $20 \%$ below the operational beam current of $100 \mathrm{~mA}$ ). The HSCU cooling capacity was clearly exceeded because the LHe pressure was rising. The heating was the same for different beam fill patterns, which ruled out resistive wall or wakefield effects and pointed to synchrotron radiation. To reduce the synchrotron radiation heat load that was coming from the upstream bending magnet, it was decided to steer the beam orbit in that magnet to increase the angle between the dipole exiting trajectory and the HSCU axis. This causes the bigger part of the radiation from the end of the bending magnet to be intercepted upstream of the HSCU. Figure 34 shows an

TABLE VII. Measured HSCU multipole components.

\begin{tabular}{lcccccc}
\hline \hline $\begin{array}{l}\text { Current } \\
(\mathrm{A})\end{array}$ & Quadrupole $(\mathrm{G})$ & $\begin{array}{c}\text { Sextupole } \\
(\mathrm{G} / \mathrm{cm})\end{array}$ & $\begin{array}{c}\text { Octupole } \\
\left(\mathrm{G} / \mathrm{cm}^{2}\right)\end{array}$ & $\begin{array}{c}\text { Skew Quadrupole } \\
\left(\mathrm{G} / \mathrm{cm}^{2}\right)\end{array}$ & $\begin{array}{c}\text { Skew Sextupole } \\
(\mathrm{G} / \mathrm{cm})\end{array}$ & $\begin{array}{c}\text { Skew Octupole } \\
\left(\mathrm{G} / \mathrm{cm}^{2}\right)\end{array}$ \\
\hline 0 & -26.2 & -4.55 & 11.4 & 9.37 & 13.6 & -1.32 \\
100 & 233 & -390 & 98.6 & -98.2 & -411 & -82.1 \\
200 & -36.4 & -682 & 257 & 28 & -234 & -178 \\
300 & -58.3 & -923 & 416 & 24.2 & -130 & -190 \\
400 & 1.81 & -1100 & 457 & -31.7 & -5.44 & -226 \\
500 & -6.28 & -1230 & 529 & -70.9 & 93.5 & -238 \\
\hline \hline
\end{tabular}




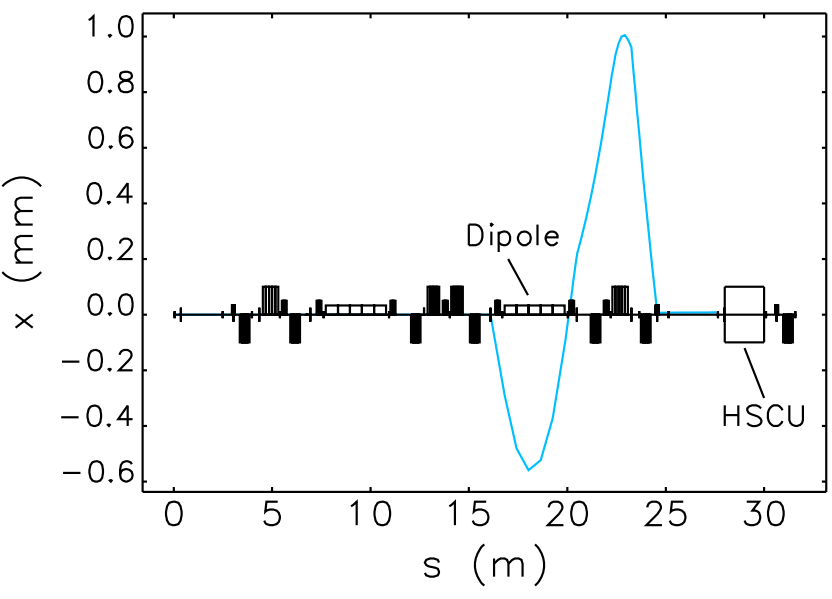

FIG. 34. Orbit bump that generates positive orbit angle at the exit of the dipole, which only spans half the sector and has small overall orbit distortion. One lattice sector is shown. The 1-mrad dipole is located at $24.5 \mathrm{~m}$ point, where the orbit bump ends.

orbit bump that provides an additional $0.5 \mathrm{mrad}$ orbit angle at the dipole exit while maintaining a relatively small orbit, with the disturbance confined to the downstream half of the lattice sector. This orbit bump succeeded in reducing the temperature of the coils and allowed the magnet to be operated at full beam current. The reason that required us to introduce this additional orbit steering to reduce the heat load is under further investigation.

After the issue with excessive heating of the magnet was resolved, the rest of the commissioning process went smoothly. Standard measurements similar to those taken with previously installed SCUs [10] were taken to ensure that the device did not degrade electron beam performance.

\section{Effect of HSCU field on the beam}

The field integrals of the HSCU were measured by recording the orbit distortion as a function of the magnet current. As was mentioned above, the first and second field integrals are largely self-compensated by the additional internal horizontal/vertical field correctors at each end of the HSCU based on the magnetic measurements in the lab. Magnetic measurements also predicted higher field integral errors at the top end of the HSCU current range, which the internal correctors could not fully compensate. Figure 35 shows first and second vertical field integrals measured with the beam with the internal corrector compensation running. The design requirements for the first and second integrals are $\pm 80 \mu \mathrm{T} \mathrm{m}$ and $\pm 100 \mu \mathrm{T} \mathrm{m}^{2}$. As was expected, the first integral exceeded requirements above $350 \mathrm{~A}$. To handle that, a small external corrector with maximum strength of $300 \mu \mathrm{Tm}$ was placed immediately upstream of the cryostat. This magnet is operated in a feedforward fashion together with an existing storage ring corrector dipole magnet downstream of the HSCU. These correcting magnets need to provide correcting fields between $35 \mu \mathrm{T} \mathrm{m}$

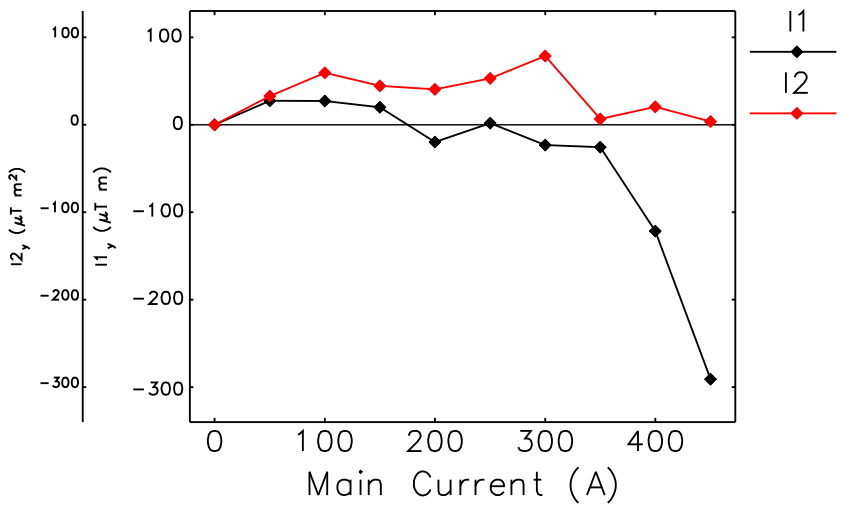

FIG. 35. First and second vertical field integrals measured with the beam with internal correctors running but without external compensation.

and $160 \mu \mathrm{Tm}$ (between $1.5 \mu \mathrm{rad}$ and $7 \mu \mathrm{rad}$ ) to keep the first integral within the requirements.

No additional $x-y$ coupling generated by this device was observed, and lifetime and injection efficiency were not affected during the operation of the HSCU. Thus, the multipole components of HSCU were declared within requirements.

Figure 36 shows orbit motion during an intentionally induced quench. The largest beam orbit transient in a straight section was $250 \mu \mathrm{m}$ in the horizontal plane and $60 \mu \mathrm{m}$ in the vertical plane. With fast orbit feedback running (which is always the case during normal APS user operations), the orbit motion was reduced to $60 \mu \mathrm{m}$ and $25 \mu \mathrm{m}$, respectively. In either case, the motion is so small that it does not affect user operations or present a risk of beam loss.

Beam dumps caused by a fault condition (unrelated to the SCUs) can potentially generate local beam losses sufficient to cause quench in the SCU. An abort kicker was installed in January 2016 to ensure that the beam is lost far from any SCU, including the HSCU [29]. Tests during commissioning showed that the beam dump did not quench the HSCU, and a year of user operation confirmed this.

When the HSCU quenches the stored energy is deposited into the LHe tank which causes the pressure in the LHe tank to increase. During the quench tests a pressure rise of $\sim 200$ Torr was observed. Recovery of the pressure to 830 Torr took approximately $45 \mathrm{~min}$ and full recovery to 760 Torr took approximately $80 \mathrm{~min}$. 830 Torr is the pressure at which the magnet can be reenergized and this prevents the pressure in the LHe tank from exceeding the relief system value in the case of back-to-back quenches. The observed recovery times are consistent with observations in the measurement laboratory.

\section{B. Radiation performance}

Characterization of the radiation produced by the HSCU began during machine studies periods in January 2018 

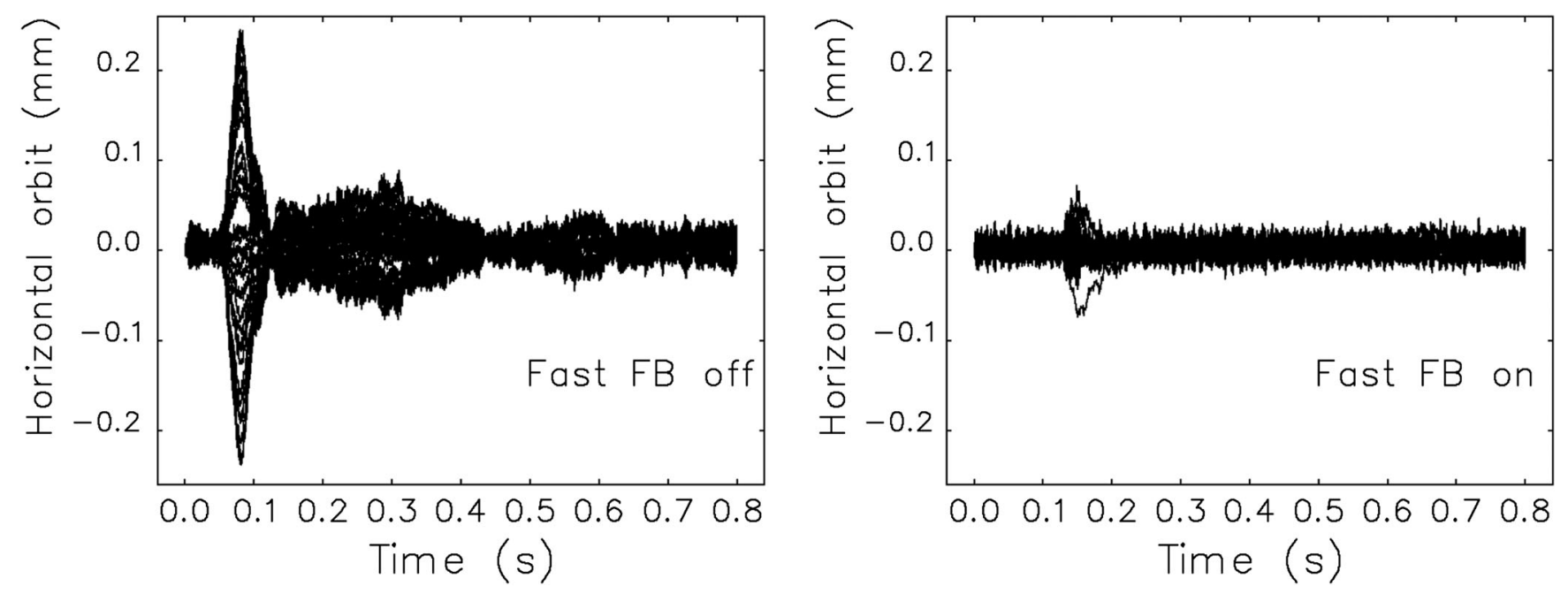

FIG. 36. Effect of induced quench on the beam orbits at all the IDs. Left panel: Slow orbit correction only. Right panel: Fast orbit feedback (FB) turned on.

and continued as APS user operations began. Many of the predicted qualities have been demonstrated. One of the most important characteristics of HSCU radiation is the suppression of all high harmonics. Figure 37 (courtesy of D. Walko) shows the simulated and measured flux through a $0.2 \mathrm{~mm}$ vertical by $0.6 \mathrm{~mm}$ horizontal aperture at $27 \mathrm{~m}$ from the source, giving an angular aperture of $7.5 \mu \mathrm{rad}$ vertical by $22 \mu \mathrm{rad}$ horizontal. It is measured with a nitrogen-filled ion chamber and with the HSCU operating at a current of $450 \mathrm{~A}$. The data are corrected for attenuation by the beamline beryllium $(750 \mu \mathrm{m})$, air $(6 \mathrm{~cm})$, and Kapton $(420 \mu \mathrm{m})$. The data were collected using a $\mathrm{Si}(111)$ monochromator, whose bandpass is $0.0134 \%$. The second harmonic is reduced compared to radiation emitted by a planar $3.3 \mathrm{~cm}$ period undulator A with the gap set for

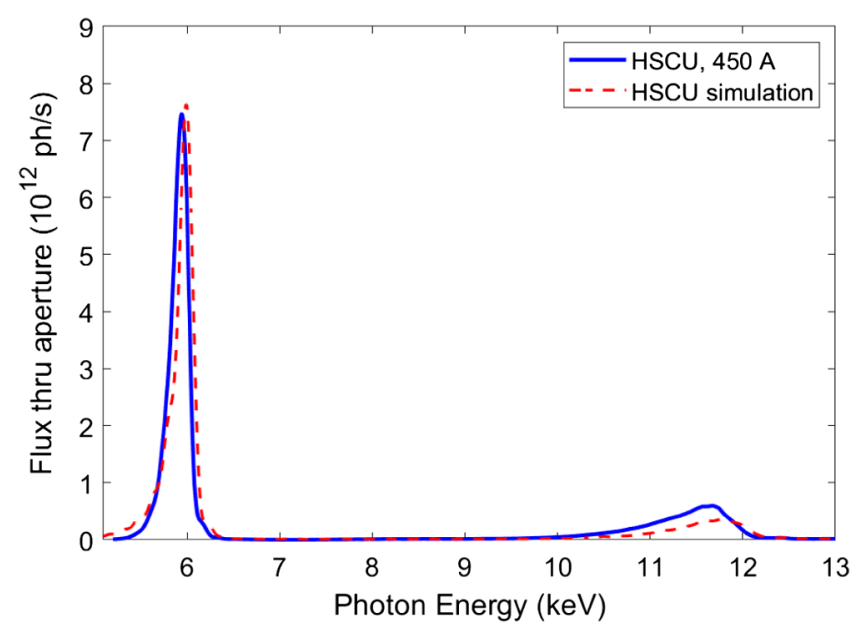

FIG. 37. Simulated and measured spectrum of HSCU with the device operating with a 450 A current. The aperture is $0.2 \mathrm{~mm}$ vertical by $0.6 \mathrm{~mm}$ horizontal at $27 \mathrm{~m}$ from the source, giving an angular aperture of $7.5 \mu \mathrm{rad}$ vertical by $22 \mu \mathrm{rad}$ horizontal. the same as the HSCU energy of the first harmonic. The third harmonic is nearly eliminated. This result confirms that pink HSCU beam could be delivered for experiments without the use of a harmonic-rejection mirror. Such a source provides a distinct advantage in coherent $\mathrm{x}$-ray imaging and $\mathrm{x}$-ray emission spectroscopy measurements.

Radiation properties of the APS HSCU have been studied in detail. The results of these studies will be published shortly in a separate paper [30]. Also, a set of successful experiments has been conducted using HSCU radiation.

In conclusion, it is important to note that the HSCU has been in user operation for two years. It has demonstrated 99.9\% reliability and has become an indispensable tool for unique $\mathrm{x}$-ray programs at the APS.

\section{ACKNOWLEDGMENTS}

The authors acknowledge the long-term continuous support and valuable contributions of the APS staff on all levels. This work is supported by the U.S. Department of Energy, Office of Science, under Contract No. DE-ACO2O6CH11357.

[1] D. F. Alferov, Yu. A. Bashmakov, and E. G. Bessonov, Generation of circularly polarized electromagnetic radiation, Sov. Phys. Tech. Phys. 21, 1408 (1976).

[2] L. R. Elias and J. M. Madey, Superconducting helically wound magnet for the free-electron laser, Rev. Sci. Instrum., 50, 1335 (1979).

[3] G. Ya. Kezerashvili, A. P. Lysenko, Yu. M. Shatunov, and P. V. Vorobyov, Colliding beam polarization measurement using superconducting helical undulator at the VEPP-2M storage ring, Nucl. Instrum. Methods Phys. Res., Sect. A 314, 15 (1992). 
[4] D. J. Scott, S. Appleton, J. A. Clarke, O. B. Malyshev, B. J. A. Shepherd, B. Todd, D. E. Baynham, T. Bradshaw, A. Brummitt, S. Carr, Y. Ivanyushenkov, J. Rochford, I. R. Bailey, P. Cooke, J. B. Dainton, L. I. Malysheva, D. P. Barber, and G. A. Moortgat-Pick, Selection of the optimum magnet design for the international linear collider positron source helical undulator, Phys. Rev. Accel. Beams 10, 032401 (2007).

[5] S. H. Kim, Magnetic field analysis of helical undulators, APS Technical Report No. LS-331, 2012.

[6] J. Fajans, End effects of a bifilar magnetic wiggler, J. Appl. Phys. 55, 43 (1984).

[7] C. Emma, K. Fang, J. Wu, and C. Pellegrini, High efficiency, multiterawatt x-ray free electron lasers, Phys. Rev. Accel. Beams 19, 020705 (2016).

[8] S. Casalbuoni, A. Cecilia, S. Gerstl, N. Glamann, A. W. Grau, T. Holubek, C. Meuter, D. S. de Jauregui, R. Voutta, C. Boffo, T. Gerhard, M. Turenne, and W. Walter, Characterization and long term operation of a novel superconducting undulator with $15 \mathrm{~mm}$ period length in a synchrotron light source, Phys. Rev. Accel. Beams 19, 110702 (2016).

[9] Y. Ivanyushenkov et al., Development and operating experience of a short-period superconducting undulator at the advanced photon source, Phys. Rev. Accel. Beams 18, 040703 (2015).

[10] Y. Ivanyushenkov et al., Development and operating experience of a 1.1-m-long superconducting undulator at the advanced photon source, Phys. Rev. Accel. Beams 20, 100701 (2017).

[11] N. A. Mezentsev, Superconducting magnet systems of Budker INP for generation of synchrotron radiation, in Workshop on Superconducting Undulators and Wigglers, 2003, http://www.esrf.eu/Apache_files/Machine/ Conferences/mezentsev.pdf.

[12] E. A. Bekhtenev, S. V. Khruschev, E. A. Kuper, V. H. Lev, N. A. Mezentsev, E. G. Miginsky, V. V. Repkov, V. A. Shkaruba, V. M. Syrovatin, and V. M. Tsukanov, A multipole superconducting wiggler for Canadian Light Source, Phys. Part. Nucl. Lett. 3, S16 (2006).

[13] J. Fuerst, Q. Hasse, Y. Ivanyushenkov, M. Kasa, and Y. Shiroyanagi, A second-generation superconducting undulator cryostat for the aps, IOP Conf. Seri.: Mater. Sci. Eng. 278, 012176 (2017).

[14] M. Kasa et al., Design, construction, and magnetic field measurements of a helical superconducting undulator for the Advanced Photon Source, in Proc. 9th International Particle Accelerator Conference (IPAC'18), Vancouver, BC, Canada, April 29-May 4, 2018, number 9 in International Particle Accelerator Conference (JACoW, Geneva, Switzerland, 2018), pp. 1263-1265, https:// doi.org/10.18429/JACoW-IPAC2018-TUPMF008.

[15] M. Borland, Use of multi-objective methods for choosing undulators for storage rings, in Proc. 3rd Int. Particle Accelerator Conf. (IPAC'12), New Orleans, LA, USA, May 2012 (JACoW Publishing, Geneva, Switzerland, 2012), pp. 1680-1682.
[16] M. Borland et al., Recent progress and plans for the code elegant, in Proc. 10th Int. Computational Accelerator Physics Conf. (ICAP'09), San Francisco, CA, August 2009, pp. 111-116, https://accelconf.web.cern.ch/ ICAP2009/papers/we3iopk02.pdf.

[17] T. Tanaka and H. Kitamura, SPECTRA: a synchrotron radiation calculation code, J. Synchrotron Radiat. 8, 1221 (2001).

[18] N. Srinivas and K. Deb, Muiltiobjective optimization using nondominated sorting in genetic algorithms, Evolutionary computation 2, 221 (1994).

[19] O. Chubar, P. Elleaume and J. Chavanne, Computing 3D magnetic fields from insertion devices, in Proceedings of the Particle Accelerator Conference, Vancouver, BC, Canada, 1997 (IEEE, New York, 1997), p. 3509.

[20] Supercon Inc, 830 Boston Turnpike Road, Shrewsbury, MA 01545, U.S.A.

[21] A. Xiao, V. Sajaev, and Y. Sun, Simulation studies of the helical superconducting undulator installed at aps, in Proceedings, 9th International Particle Accelerator Conference (IPAC 2018): Vancouver, BC Canada, 2018, p. TUPMF018, https://doi.org/10.18429/JACoWIPAC2018-TUPMF018.

[22] W. G. Jansma, J. D. Fuerst, K. A. Goetze, and J. E. Rix, Precision 2d laser scanning: Overview and applications, J. CMSC 12, 6 (2017).

[23] Y. Shiroyanagi, J. Fuerst, Q. Hasse, and Y. Ivanyushenkov, Thermal modeling and cryogenic design of a helical superconducting undulator cryostat, in Proceedings, 2nd North American Particle Accelerator Conference (NAPAC2016): Chicago, Illinois, USA, p. THA1CO05, 2017, https://accelconf.web.cern.ch/napac2016/papers/ tha1co05.pdf.

[24] K. Harkay, J. Fuerst, and M. Kasa, Beam-induced heating on the helical superconducting undulator(hscu) test chamber, Advanced Photon Source Technical Report No. ASD-AOP-2017-051, September 2017.

[25] Y. Shiroyanagi, J. Fuerst, Q. Hasse, M. Kasa, I. Kesgin, and Y. Ivanyushenkov, Thermal analysis of a helical superconducting undulator cryostat, IEEE Trans. Appl. Supercond. 29, 8 (2019).

[26] C. Doose and M. Kasa, Magnetic measurements of the first superconducting undulator at the Advanced Photon Source, in Proc. of North American Particle Accelerator Conf. 2013 (2013), p. 1238, THPBA06.

[27] M. Kasa, Dsp methods for correcting dispersion and pulse width effects during pulsed wire measurements, Measurement 122, 224 (2018).

[28] Senis, Hertizentrum 11, 6300, Zug, Switzerland.

[29] K. C. Harkay, J. C. Dooling, V. Sajaev, and J. Wang, Operational experience with beam abort system for superconducting undulator quench mitigation, in Proc. of North American Particle Accelerator Conf. 2016, 2016, https://accelconf.web.cern.ch/napac2016/papers/ wepob05.pdf.

[30] D. Walko (private communication). 